\title{
Rules of ProOF, COURTS, AND InCENTIVES
}

\author{
DOMINIQUE DEMOUGIN \\ Claude Fluet
}

\section{CESIFO WORKING PAPER No. 2014 \\ CATEGORY 9: INDUSTRIAL ORGANISATION \\ JUNE 2007}

Presented at CESifo Area Conference on Applied Microeconomics, March 2007

An electronic version of the paper may be downloaded

- from the SSRN website:

- from the RePEc website:

www.SSRN.com

- from the CESifo website:

Www.RePEc.org

www.CESifo-group.de 


\title{
RULES OF PROOF, COURTS, AND INCENTIVES
}

\begin{abstract}
We analyze the design of legal principles and procedures for court decision-making in civil litigation. The objective is the provision of appropriate incentives for potential tort-feasors to exert care, when evidence about care is imperfect and may be distorted by the parties. Efficiency is shown to be consistent with courts adjudicating on the basis of the preponderance of evidence standard of proof together with common law exclusionary rules. Inefficient equilibria may nevertheless also arise under these rules. Directing courts as to the assignment of the burden of proof is then useful as a coordination device. Alternatively, burden of proof guidelines are unnecessary if courts are allowed a more active or inquisitorial role, by contrast with that of passive adjudicator.
\end{abstract}

JEL Code: D8, K4.

Keywords: evidentiary rules, standard of proof, burden of proof, inquisitorial, adversarial, discovery, deterrence.

\author{
Dominique Demougin \\ Humboldt University Berlin \\ School of Business and Economics \\ Spandauer Str. 1 \\ 10178 Berlin \\ Germany \\ demougin@wiwi.hu-berlin.de
}

\author{
Claude Fluet \\ University of Quebec at Montreal \\ Economics Department \\ C.P. 8888, Suc. Centre-Ville \\ Montreal H3C $3 P 8$ \\ Canada \\ fluet.claude-denys@ugam.ca
}

September 2006

Preliminary versions of this paper were presented at the Workshop on Law and Economics, Stony Brook Game Theory Festival, July 2005, and at the EALE Annual Conference, Madrid, September 2006. We thank Andrew Daugherty, Chris Sanchirico, Steve Mongrain, HansBernd Schäfer, Kathryn Spier, Eric Talley and Joel Watson for helpful comments. Financing from FQRSC (Quebec) and SSHRC (Canada) is gratefully acknowledged. 


\section{Introduction}

Court decision-making is constrained by various rules and standards. In common law, exclusionary rules discard as inadmissible apparently relevant evidence. This includes evidence of similar facts (e.g., whether the defendant was previously involved in a similar case), evidence of character or of a reputation for behaving negligently or diligently, or evidence purporting to show that defendants of a particular type tend to behave in a particular way. In civil litigation, courts must decide on the basis of a preponderance of evidence, a standard of proof requirement. The preponderance standard means that a claim is deemed proved if, upon the evidence, it is more likely true than not true. There are also situations where the law imposes on courts the burden of proof assignment. For instance, rather than having the plaintiff bear the burden as is usually the case, statute law or jurisprudence may require that the defendant prove that he did not cause harm or did not act negligently. In some cases, burden of proof requirements may also refer to the type of evidence needed for proof. Finally, there are legal traditions where the court is allowed a more active or inquisitorial role, by contrast with that of passive adjudicator in the purely adversarial procedure of common law. We develop a model of tort litigation where the above legal principles and procedures can be analyzed on efficiency grounds.

To illustrate, consider a medical liability case. The plaintiff claims that he suffered harm due to negligent oversight by his physician. Suppose all relevant evidence always becomes available to the court. The evidence may nevertheless be highly imperfect, i.e., the court faces a risk of error whether it rules in favor of the patient or the physician. An important issue is therefore the "degree of certainty" or standard of proof required to reach a decision. Demougin and Fluet (2006) show that the preponderance standard has a remarkable property. If courts rule on the issue of negligence on a preponderance of evidence, there will be maximum ex ante incentives for physicians to act nonnegligently. The argument has a caveat: in applying the standard, courts must abide by exclusionary rules. Evidence pertaining to a 
"propensity" for the defendant to act a certain way should be discarded as inadmissible. There is therefore an efficiency justification for the standard of proof and exclusionary rules in common law. ${ }^{1}$

The above result was derived under the assumption that evidence exogenously becomes available to the court. This paper extends the analysis to the case where verifiable evidence initially rests with the parties, who may attempt to shade the evidence. This introduces additional difficulties such as the weight that should be given to a testimony or the appropriate interpretation of the evidence submitted. If evidence can be manipulated, is a preponderance of evidence still the appropriate standard? And what does a preponderance mean?

The issue is straightforward if both litigants are known to have access to all verifiable evidence and if submission costs are small compared to the stakes. As evidence will necessarily favor one party or the other, one of the "interested party" will find it useful to disclose it (Milgrom and Roberts, 1986). Equivalently, if all relevant evidence is not disclosed, a Bayesian judge or jury will draw the appropriate inferences. However, unraveling does not follow if the parties do not always have access to all the evidence and may be unequally informed. Shavell (1989) and Shin (1994, 1998) showed that the parties may then be successful in not revealing facts harmful to their case.

The court's problem is then to interpret partial and possibly distorted information. Should this affect the standard of proof and exclusionary rules described above? If plaintiffs in medical liability cases are known to be able on average to present only basic evidence, should the standard of proof they must meet be lower? Should some weight now be given to the physicians' general propensity to act negligently? We show that, even though the parties can manipulate the submitted evidence and may be unequally informed, courts should abide by exactly the same rules of proof as above.

We assume that, in applying these rules, courts are sophisticated decision-

\footnotetext{
${ }^{1}$ Schrag and Scotchmer (1994) analyzed the deterrence justification for the dismissal of character evidence in criminal trials. Sanchirico (2001b) provides an in-depth discussion.
} 
makers, i.e., they understand the parties' strategic incentives. As a result, they interpret limited evidence in a particular light. Suppose the plaintiff submits "mixed" evidence. By this we mean evidence which, under the preponderance standard, is consistent with either a decision for the plaintiff or against him, should additional evidence be forthcoming. Then it may be that, if the defendant does not come forward with countervailing evidence, the court will form a presumption against him. Such presumptions arise spontaneously, so to speak, in the manner courts interpret evidence under the preponderance standard.

So far, the implication seems to be that standard of proof and exclusionary rules are the only judicial tools needed to efficiently direct court decisionmaking, i.e., these principles are sufficient if the objective of tort law is to provide potential tort-feasors with the best ex ante incentives to exert care. There is nevertheless a sense in which the foregoing result does not necessarily follow. While an efficient equilibrium exists when courts operate under the appropriate standard of proof and exclusionary rules, other equilibria may exist as well under the same set of rules.

To see this, suppose again the victim most likely has access to only limited evidence. Assume that efficiency requires that the defendant be held liable given this evidence on its own. If in equilibrium the court holds a presumption against the defendant when this evidence is the only one submitted, then the victim will sue on the basis of this evidence alone. Moreover, the court will be justified, under the preponderance standard, to find that there was negligence. The reason is that, owing to the presumption against him, the defendant would most likely have come forward with additional evidence if it was in his favor. The fact that he did not therefore justifies the presumption. Call this equilibrium A, which by assumption here is the efficient one.

Now, consider another possibility. In equilibrium B, the court does not find the defendant liable under the limited evidence alone. Hence, the victim does not sue on this basis alone. If he did, the defendant would have no incentive to come forward with additional costly evidence since he (correctly) 
expects the plaintiff to fail. Thus, the court will interpret the limited evidence differently than in equilibrium A, because the defendant's strategic incentives are different. As a result, the court concludes that the plaintiff's evidence does not meet the standard of proof, i.e., that negligence has not been shown to be more likely than due care.

In circumstances such as these, imposing on courts the burden of proof assignment helps select the better equilibrium. In the example, courts should be directed to put the burden of proof on the defendant. The purpose is to coordinate parties and courts on the good equilibrium, making sure that victims come forward even if it they have limited evidence. Such guidelines - e.g., through statute law or jurisprudence from higher courts - are often observed. Although we formulated the example in terms of the need to put the burden of proof on the defendant, the reverse problem can also arise where courts are too lenient with plaintiffs. ${ }^{2}$

Burden of proof guidelines apply to large classes of cases, irrespective of the detailed information only available at the court level. Hence, guidelines will not always ensure coordination on the efficient equilibrium. This leads us to inquire whether a modified court procedure can eliminate the need for guidelines. Up to now, our stylized court involved a purely "passive" adjudicator whose only role is to decide at the close of the proceedings. The modified procedure, as in the more "inquisitorial" trials of civil law countries, allows the adjudicator to intervene during the proceedings by interrogating the parties directly and purposely shifting the burden of proof. Specifically, the adjudicator announces how he will rule should no additional evidence be forthcoming (both binding and non binding announcements are considered). We show that the optimal liability assignment then obtains as the unique equilibrium if the active adjudicator abides by the preponderance standard and common law exclusionary rules. The interpretation is that, with a more

\footnotetext{
${ }^{2}$ In our analysis as in actual practice, the plaintiff always bears the so-called "primary burden". Since he initiates the suit, he must provide some appropriate, albeit limited evidence if he is to stand a chance of winning.
} 
active court, these rules of proof then suffice for an efficient "decentralization" of decisions regarding liability.

The paper develops as follows. Section 2 describes the basic tort situation that we have in mind. The next two sections assume that society can commit to a liability assignment as a function of the disclosed evidence, without yet introducing courts as ex post decision-makers. Section 3 analyzes the optimal scheme for the purpose of inducing care, i.e., we determine how liability should be assigned on the basis of the evidence made available by the parties. The liability assignment takes into account the potential tort-feasors' ex ante incentives to exert care and the parties' ex post incentives to submit and manipulate evidence. We show that the optimal scheme satisfies a "morelikely-than-not" property. Section 4 discusses how the mechanism can also be interpreted in terms of the allocation of the burden of proof. Section 5, which contains the main results, examines whether the optimal liability assignment can be obtained as an equilibrium when decisions regarding liability are delegated to a court, now an additional player in the game. This requires that we analyze what general legal rules should constrain court decision-making. We show that the appropriate rules include the preponderance of evidence standard of proof and exclusionary rules as in common law. We discuss the

need for burden of proof assignments as coordination device and the role of more inquisitorial courts. Section 6 reviews the related literature, discusses extensions, and concludes. Proofs are in the appendix unless statements are obvious from the text.

\section{The Model}

A party, denoted $D$, undertakes a socially valuable activity which may impose harm on a third party, denoted $P$, depending on how the activity is undertaken. If $D$ exerts high care $h$, no harm is imposed. If low care $l$ is taken, $P$ suffers a loss of amount $L$. With low care $D$ obtains a private benefit $c$, for instance the cost savings from not exerting high care. When 
$c<L$, low care is socially undesirable. The cost $c$ is distributed according to the cumulative distribution function $G(c)$, but it is privately known to $D$ at each instance where a choice of care level must be made. Thus, if $D$ were fully liable whenever he causes harm, he would exert high care in all instances where $c<L$, hence with probability $G(L)$, which would be socially optimal.

The occurrence of harm, equivalently whether $D$ undertook action $l$, is not directly verifiable. Only some body of evidence, denoted by $x$, is available. This may include witness testimony about $D$ 's behavior, expert opinion about whether $P$ suffered harm, documents, etc. Ex ante, the content of the evidence $x$ is uncertain with potential realizations in a countable set $X$ and a probability distribution that depends on $D$ 's care level. We denote this probability by $p_{j}(x)$, where $j$ is either $h$ or $l$, so that $\sum_{x \in X} p_{j}(x)=1$. In this formulation, it is possible that some realizations of the evidence reveal $D$ 's behavior or the occurrence of harm perfectly. This occurs when $p_{h}(x)=0$ and $p_{l}(x)=1$ or conversely when $p_{h}(x)=1$ and $p_{l}(x)=0$. If this were true for all $x \in X$, the evidence would be fully informative. We assume this is not the case. ${ }^{3}$

To illustrate, suppose $P$ has utility function $u=\ln q+w$ where $w$ is wealth and $q$ is an index of physical well-being, say the individual's health status. If the physician or hospital takes high care, the potential health status is the random variable $\widetilde{q}_{h}$ while with low care it is $\widetilde{q}_{l}=\beta \widetilde{q}_{h}$, where $\beta<1$. In money equivalents, the loss due to low care is $L=-\ln \beta$. If the only evidence were the individual's health status, i.e., $x=q$, this would generally constitute relatively poor evidence about the physician's care, depending on the extent to which the supports of $\widetilde{q}_{h}$ and $\widetilde{q}_{l}$ overlap. However, $x$ could also include additional direct evidence about the physician's actions.

Party $P$ (now the plaintiff) can sue party $D$ (now the defendant) but can hope to prevail only by submitting evidence. We first consider the case

\footnotetext{
${ }^{3}$ We assume $p_{h}(x)+p_{l}(x)>0$ for all $x \in X$ (i.e., $X$ is the union of the supports of the two distributions).
} 
where the parties have perfect access to the evidence $x$, assuming that the cost of submitting evidence is negligible. The issue is how liability should be assigned, on the basis of the evidence, in order to induce $D$ to exert optimal care as often as possible. We impose the constraint that the defendant cannot be held liable for more than the possible loss (we discuss below the effect of allowing "punitive damages"). Let $\psi(x) \in[0,1]$ denote the liability assignment. $\psi(x)=1$ means that the defendant is held liable for the full amount $L$ when the evidence is $x, \psi(x)=0$ that he is not liable, while a value between zero and unity amounts to randomization or to damages for only a fraction of the potential harm.

For a given liability assignment function, $D$ 's expected liability costs are

$$
L \sum_{x \in X} p_{j}(x) \psi(x), \quad j=h, l .
$$

Taking the cost $c$ into account, $D$ therefore chooses not to impose harm if

$$
\delta \equiv \sum_{x \in X}\left[p_{l}(x)-p_{h}(x)\right] \psi(x) \geq \frac{c}{L} .
$$

The expression on the left-hand side, which we refer to as deterrence, is the increase in the probability of being held liable when action $l$ is chosen rather than $h$.

It is easily seen that $\delta \leq 1$ under any $\psi$, a value of unity being feasible only if the evidence perfectly reveals $D$ 's behavior. With imperfectly informative evidence, high care is exerted only when $c \leq \delta L<L$, which means that there is insufficient deterrence. The best liability assignment function is therefore the one which maximizes deterrence equivalently, which maximizes the probability $G(\delta L)$ that no harm is caused.

Proposition 1 The deterrence maximizing liability assignment, as a function of the evidence $x \in X$, is $\psi^{*}(x)=1$ when $p_{l}(x)>p_{h}(x), \psi^{*}(x)=0$ otherwise.

To maximize deterrence, $\psi(x)$ should be set at its maximum value of unity when the expression in brackets in (1) is positive, and at its minimum 
value of zero when the expression is negative. When the expression is nil, the value of $\psi(x)$ is indifferent. We set it equal to zero in this case, which may be interpreted as putting the burden of persuasion on the plaintiff. ${ }^{4}$

The proposition has a straightforward interpretation. $p_{j}(x)$ is the probability of the "data" represented by $x$ conditionally on the hypothesis $j \in$ $\{h, l\}$ being true. In statistical terminology, it would be referred to as the "likelihood" of hypothesis $j$ on the basis of the observable data. Thus, the proposition states that the defendant should be liable when $l$ is more likely than $h$, given the evidence. Under such a scheme and given a small cost of submitting evidence, when $p_{l}(x)>p_{h}(x)$ the plaintiff files suit and submits $x$, otherwise he does not file suit.

Consider now the possibility of punitive damages $B>L$. A sufficiently large $B$ can obviously implement the first best provided we do not run into bankruptcy problems. The potential defendant now exerts high care if

$$
c \leq B \sum_{x \in X}\left[p_{l}(x)-p_{h}(x)\right] \psi(x) .
$$

Optimal care requires that $B$ be set so that

$$
L=B \sum_{x \in X}\left[p_{l}(x)-p_{h}(x)\right] \psi(x) .
$$

This can be satisfied in an infinite number of ways, but clearly $\psi^{*}$ leads to the smallest level of punitive damages, say $B^{*}$, consistent with the first best. Thus, another justification for the liability assignment function of proposition 1 is that it minimizes the punitive damages consistent with inducing optimal care. $^{5}$ Alternatively, it may be that the defendant's wealth is smaller than $B^{*}$, so that the first-best is unattainable. Holding the defendant liable up to

\footnotetext{
${ }^{4}$ The result is borrowed from Demougin and Fluet (2006) - see also Lando (2002) for a similar finding. Note that society is asumed to be indifferent to error per se. If error were socially costly, $\psi$ should take into account the trade-off between deterrence and avoiding error (see Demougin and Fluet, 2005).

${ }^{5}$ Large punitive damages generate other distorsions since they inflate the cost of engaging in the risky activity, e.g., becoming a physician.
} 
his entire wealth and using $\psi^{*}$ is then the best one can do. In what follows, we stick to our earlier interpretation and assume compensatory damages, i.e., a liable defendant pays the plaintiff the amount $L$.

We henceforth relax the assumption that the parties have perfect access to all the potential evidence. To discard straightforward unraveling results, we also assume that society, as Principal, does not know the extent of the verifiable evidence available to the parties. To make things as simple as possible, suppose the complete body of evidence can be partitioned as $x=$ $(y, z)$ with $y \in Y$ and $z \in Z(y)$ defined as the set of potential additional evidence consistent with the partial evidence $y$. Both parties always have access to $y$, but may not be able to also submit $z$. For example, the potential evidence could consist of the content of two separate "files". The parties always have access to the first file $y$ but may not be able to access the second file $z$. Moreover, the parties may differ in their capacity to present verifiable evidence. Party $P$ has access to $z$ only with probability $v$, party $D$ only with probability $u$, where $u, v \in(0,1)$.

Any reasonable liability assignment scheme requires that $P$ submit at least $y$ in order to prevail. Indeed, $P$ is the only party with an interest in initiating proceedings and it is known that part $y$ of the evidence is accessible to him. However, as parties may be only partly informed, when only $y$ is disclosed society does not know whether this is because the parties did not observe all the potential evidence or whether an informed party chose not to disclose $z$. We denote by $\phi$ the case where society does not receive the additional evidence. Note that we make the usual assumption that false evidence cannot be fabricated.

The issue is now to choose a liability assignment scheme of the form $\psi(y, z) \in[0,1]$ where $y \in Y, z \in Z(y) \cup\{\phi\}$. Although the objective remains that of providing the best ex ante incentives to exert care -i.e., maximize deterrence - account must now be taken of the fact that $\psi$ will also affect the parties' ex post incentives to disclose evidence. In turn, this will have repercussions on $D$ 's ex ante incentives to exert care. 


\section{Optimal Liability Assignment}

The set-up is described by the following time line. First, society chooses at the outset a function $\psi$ for assigning liability, should $P$ file suit (no damages are paid if no suit is filed). Second, Nature chooses $c$ according to the distribution $G(c), D$ observes $c$ and decides between action $h$ or $l$. Third, Nature chooses the evidence $x=(y, z)$ according to the joint probability distribution $p_{j}(y, z)$ depending on whether $j$ is $h$ or $l$, where $y \in Y$ and $z \in Z(y)$. Fourth, $P$ (respectively $D$ ) observes $z$ with probability $v$ (respectively $u$ ); neither party knows whether the other has seen the complete potential evidence.

At this point, party $P$ decides whether to file suit, where filing suit entails the submission of $y$. We call this the filing stage. Next, if a suit has been filed, both parties decide simultaneously whether to submit additional evidence (if they can). We call this the disclosure stage. Finally, society assigns liability according to $\psi$ on the basis of the overall evidence submitted, $(y, z)$ or $(y, \phi)$ as the case may be. Notice that we do not yet discuss courts, but merely seek to characterize the deterrence maximizing liability assignment. ${ }^{6}$ Figure 1 summarizes the time line.

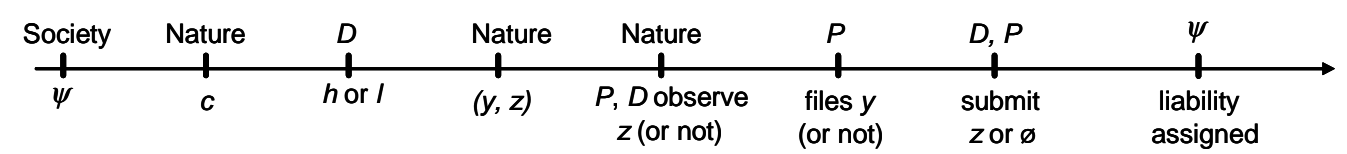

Figure 1: Liability assignment function $\psi$

Solving the game backwards, we first analyze the stages consisting of the decision to file suit and the ensuing disclosure game. As before, submitting evidence is assumed to involve an arbitrarily small cost (we further discuss the role of submission costs at the end of the section). Such a cost is incurred by $P$ if he files suit and submits $y$. A similar cost is also incurred by any party submitting the additional evidence $z$. It is easily seen that the parties then

\footnotetext{
${ }^{6} \psi$ has the same interpretation as the "sanctioning function" in Shavell (1989), except that our sanction is a transfer from the defendant to the plaintiff.
} 
have dominant strategies. For instance, suppose the victim filed suit and the injurer observed $z$. If $\psi(y, z)<\psi(y, \phi)$ the injurer discloses $z$ since by doing so he reduces the probability of paying damages. If $\psi(y, z) \geq \psi(y, \phi)$ he does not reveal $z$. Note that a party's belief as to whether the other party has observed $z$ is irrelevant; the same is true of the victim's belief about the defendant's care level. ${ }^{7}$

Lemma 1 The following strategy pair is the unique equilibrium of the file and disclosure game. (i) If $P$ observes $z$ and $\psi(y, \phi)<\psi(y, z), P$ files suit and discloses $z$ at the next stage; if $z$ is not observed or if $\psi(y, z) \leq \psi(y, \phi), P$ files suit provided $\psi(y, \phi)>0$ but submits nothing at the next stage; in all other cases $P$ does not file suit. (ii) If a suit has been filed and $\psi(y, z)<\psi(y, \phi)$, $D$ discloses $z$ if he can; otherwise he discloses nothing.

We denote by $\bar{p}_{j}(y)$ the marginal probability of partial evidence $y$, given that $D$ has chosen action $j$. We write $p_{j}(z \mid y)$ for the conditional probability of the additional evidence $z \in Z(y)$, given that the partial evidence is $y$ and that care was $j$.

Conditional on $y$, the probability of $D$ being held liable, when care level $j$ was exerted, is equal to

$$
\begin{aligned}
e_{j}(y):=\psi(y, \phi) & +v \sum_{z \in Z(y)} p_{j}(z \mid y) \max [0, \psi(y, z)-\psi(y, \phi)] \\
& -u \sum_{z \in Z(y)} p_{j}(z \mid y) \max [0, \psi(y, \phi)-\psi(y, z)]
\end{aligned}
$$

The expression follows directly from the outcome of the disclosure game, taking into account each parties' probability of accessing the complete evidence

\footnotetext{
${ }^{7}$ Bull and Watson (2004) develop a model where "verifiability" is associated with the enforcer's actual observation of hard evidence. Taking $y$ as given, think of each realization $z \in Z(y)$ as a particular "document". The random draws with probability $u$ or $v$ determine whether $D$ or $P$ possesses the document. The document $z$ is verifiable by the enforcer (i.e., will actually be observed by him) if $D$ has the document and $\psi(y, z)>\psi(y, \phi)$ or if $P$ has it and $\psi(y, z)<\psi(y, \phi)$.
} 
and the incentives to disclose (the derivation is in the proof of proposition $2)$. Ex ante, as a function of the level of care, the probability of being held liable is therefore $\sum_{y \in Y} \bar{p}_{j}(y) e_{j}(y)$.

As in section 2, the best scheme is the one which maximizes the difference in the probability of being held liable when low rather than high care is exerted. This means that $\psi$ must be chosen so as to maximize deterrence, now written as

$$
\delta=\sum_{y \in Y}\left[\bar{p}_{l}(y) e_{l}(y)-\bar{p}_{h}(y) e_{h}(y)\right]
$$

Proposition 2 When the parties may be only partly informed, deterrence is maximized by $\psi^{*}(y, z)$ as defined in proposition 1 when $z \in Z(y), \psi^{*}(y, \phi)=$ 1 if $\bar{p}_{l}(y) Q_{l}(y)>\bar{p}_{h}(y) Q_{h}(y)$ and $\psi^{*}(y, \phi)=0$ otherwise, where

$$
\begin{array}{r}
Q_{j}(y) \equiv(1-v)(1-u)+(1-u) v \sum_{z \in Z(y)}\left[1-\psi^{*}(y, z)\right] p_{j}(z \mid y) \\
+(1-v) u \sum_{z \in Z(y)} \psi^{*}(y, z) p_{j}(z \mid y), \quad j=h, l .
\end{array}
$$

The expression in (4) is the conditional probability of $z$ not being revealed given $D$ 's care level and the realization $y$. The rationale is that $z$ remains undisclosed either because both parties are uninformed or only one is informed but would not disclose evidence unfavorable to his case. $\bar{p}_{j}(y) Q_{j}(y)$ is therefore the probability of the event "partial evidence is $y$ and $z$ not revealed" given D's ex ante action. Recalling statistical terminology once more, the expression is the likelihood of action $j$ on the basis of the available "data". Thus, the proposition shows that the more-likely-than-not property still holds even when disclosure is an issue. However, the probability assessments now take into consideration the parties' capability of submitting evidence and their motive for not disclosing. ${ }^{8}$ Notice that $\psi^{*} \in\{0,1\}$ as in the previous section, i.e., the liability assignment is all-or-nothing.

\footnotetext{
${ }^{8}$ The result is derived for a binary partition of the body of evidence, but the argument obviously extends to finer partitions.
} 
Small submission costs ensured a unique equilibrium in the file and disclosure game. However, the non uniqueness that would arise with zero costs is inconsequential, i.e., $\psi^{*}$ is also deterrence maximizing if submission costs are nil. For instance, when $\psi^{*}(y, z)=\psi^{*}(y, \phi)$, an informed defendant would be indifferent between disclosing and not disclosing. Whether he does or not, the liability assignment and therefore deterrence remain the same.

A more interesting extension is when the cost of submitting $z$ is non negligible. Recalling that $\psi^{*}$ is all-or-nothing, the disclosure strategies described in lemma 1 remain dominant strategies as long as the cost of submitting $z$ is smaller than the stakes represented by $L$. It follows that $\psi^{*}$ is still deterrence maximizing. We henceforth continue to assume that the cost of filing suit and submitting $y$ is small, but allow that of submitting $z$ to be non negligible. ${ }^{9}$ The interpretation is that $y$ concerns the basic facts of the case and is straightforward to submit, while $z$ involves more complex evidence. Although submission costs play no role at this stage, they will be relevant when we discuss court decision-making.

\section{Burden of Proof}

In legal terminology, the plaintiff is said to bear the burden of proof if he loses unless he produces enough evidence supporting his claim. Conversely, the burden rests on the defendant if he is held liable unless he produces evidence in his favor. The procedure is nevertheless always initiated by the plaintiff who bears the "primary burden" of establishing that the case is worth hearing. In the model, this is captured by the fact that the plaintiff must file suit in order to obtain damages and cannot but submit $y$ when a suit is filed. In what follows, the burden of proof (or so-called "burden of production") refers to how the task of producing the additional evidence is

\footnotetext{
${ }^{9}$ However, we assume it is not too large, otherwise it could be relevant for society to consider the trade-off between deterrence and litigation costs, an issue we wish to avoid at this point. We discuss it in the conclusion.
} 
apportioned between the parties.

Given the partial evidence $y$, the scheme assigns the burden to the plaintiff if $\psi^{*}(y, \phi)=0$ and to the defendant if $\psi^{*}(y, \phi)=1$. There is a qualification. It may be that none of the parties has an incentive to submit additional evidence because $\psi^{*}(y, z)=\psi^{*}(y, \phi)$ for all $z \in Z(y)$. This occurs when $z$ is insufficiently informative compared to $y$. We say that $y$ constitutes mixed evidence if there exists $z, z^{\prime} \in Z(y)$ such that $p_{l}(y, z)>p_{h}(y, z)$ and $p_{l}\left(y, z^{\prime}\right) \leq p_{h}\left(y, z^{\prime}\right)$, implying that the liability assignment can go either way depending on what additional evidence is submitted. Otherwise, $y$ represents conclusive evidence. ${ }^{10}$

When $y$ is conclusive, either $p_{l}(y, z)>p_{h}(y, z)$ for all $z \in Z(y)$, yielding $\bar{p}_{l}(y)>\bar{p}_{h}(y)$, or $p_{l}(y, z) \leq p_{h}(y, z)$ for all $z \in Z(y)$, yielding $\bar{p}_{l}(y) \leq \bar{p}_{h}(y)$. Moreover, $Q_{h}(y)=Q_{l}(y)$ as is easily seen from (4). Disclosing additional evidence then cannot change the liability assignment. By contrast, when $y$ is mixed, one of the parties benefits from disclosing additional evidence in his favor. Thus, $\psi^{*}(y, \phi)$ captures the concept of burden of proof only when the partial evidence is mixed. The next results characterize the optimal liability assignment.

Corollary 1 If $y$ is conclusive or if $u=v, \psi^{*}(y, \phi)=1$ if $\bar{p}_{l}(y)>\bar{p}_{h}(y)$, otherwise $\psi^{*}(y, \phi)=0$.

When the partial evidence is conclusive, disclosing additional evidence is irrelevant. Liability is then assigned according to the likelihood of $l$ versus $h$ computed on the basis of the "raw" marginal probabilities. When $u=v$, disclosing evidence may benefit a party, but strategic incentives to conceal evidence cancel out. The burden of proof is then assigned on the basis of the "raw" marginal probabilities. ${ }^{11}$

\footnotetext{
${ }^{10}$ Note that evidence is labelled conclusive in terms of the more-likely-than-not criterion. It need not be perfectly informative.

${ }^{11}$ From (4), when $u=v<1, Q_{j}(y)=1-u$ for all $y \in Y, j=h, l$.
} 
Corollary 2 If $y$ is mixed, $\psi^{*}(y, \phi)=1$ if $u$ is sufficiently larger than $v$, $\psi^{*}(y, \phi)=0$ if $v$ is sufficiently larger than $u$ and $p_{l}(y, z)<p_{h}(y, z)$ for some $z \in Z(y)$.

When $y$ is mixed, the burden of proof depends on the parties' likely access to the additional evidence. The burden tends to be on the better informed party, but taking into account the "raw" information content of $y .{ }^{12}$ We illustrate the results through an example.

\section{An example}

Let the evidence set be $X=\{a, b, c, d, e, f\}$ with probabilities given as in the first two lines of table 1 . The third line gives the likelihood ratio of $l$ versus $h$ on the basis of the complete evidence. Under the optimal scheme, the defendant is liable if $x=e$ or $f$. The partial evidence $y$, in the middle part of the table, corresponds to a coarser partition of the complete evidence. The realization $c d$ is conclusive evidence in favor of $D$ (i.e., it does not matter whether the complete evidence is $c$ or $d$ ), so that $P$ would not sue when observing $y=c d$. By contrast, af and be represent mixed evidence.

The bottom part of the table gives the likelihood ratio of $l$ versus $h$ under partial evidence and taking into account the parties' strategic incentives to disclose under the optimal scheme, i.e., the ratio is

$$
\frac{\bar{p}_{l}(y) Q_{l}(y)}{\bar{p}_{h}(y) Q_{h}(y)}
$$

where $Q_{h}$ and $Q_{l}$ are as defined in proposition 2 .

\footnotetext{
${ }^{12}$ The asymmetry in corollary 2 is due to the fact that mixed evidence is consitent with $p_{l}(y, z) \geq p_{h}(y, z)$ for all $z \in Z(y)$. The burden of proof should then be on the defendant irrespective of $u$ or $v$. Indeed, no deterrence is lost due to the possibility that the defendant may not be able to submit evidence showing that $h$ is as likely as $l$ (recall the discussion of proposition 1). By contrast, putting the burden on the plaintiff (i.e., setting $\psi(y, \phi)=0$ ) would entail less deterrence, given the risk that the plaintiff could not produce additional evidence showing that $l$ is more likely than $h$.
} 
When $u=v$, this likelihood ratio is the "naive" ratio $\bar{p}_{l}(y) / \bar{p}_{h}(y)$ already shown in the middle part of the table. Submissions are taken at their face value. In this case, an uninformed plaintiff would sue only when $y=a f$. The burden of proof is then on the defendant to disclose $a$ if he can. If informed, the plaintiff would also sue when $y=b e$ and $x=e$; that is, he would file suit by submitting be and then submit $e$ in a second step. The burden of proof is then on the plaintiff.

Table 1: Burden of Proof

\begin{tabular}{|c|c|c|c|c|c|c|}
\hline & \multicolumn{6}{|c|}{ Evidence $x=(y, z)$} \\
\hline & $a$ & $b$ & $c$ & $d$ & $e$ & $f$ \\
\hline$p_{h}(x)$ & 0.068 & 0.222 & 0.340 & 0.170 & 0.190 & 0.010 \\
\hline$p_{l}(x)$ & 0.004 & 0.042 & 0.328 & 0.166 & 0.330 & 0.130 \\
\hline \multirow[t]{3}{*}{$p_{l}(x) / p_{h}(x)$} & 0.059 & 0.189 & 0.965 & 0.976 & 1.737 & 13.00 \\
\hline & \multicolumn{6}{|c|}{ Partial evidence $y$} \\
\hline & \multicolumn{2}{|c|}{$a f$} & \multicolumn{2}{|c|}{ be } & \multicolumn{2}{|c|}{$c d$} \\
\hline $\bar{p}_{h}(y)$ & \multicolumn{2}{|c|}{0.078} & \multicolumn{2}{|c|}{0.412} & \multicolumn{2}{|c|}{0.510} \\
\hline $\bar{p}_{l}(y)$ & \multicolumn{2}{|c|}{0.134} & \multicolumn{2}{|c|}{0.372} & \multicolumn{2}{|c|}{0.494} \\
\hline \multirow[t]{3}{*}{$\bar{p}_{l}(y) / \bar{p}_{h}(y)$} & \multicolumn{2}{|c|}{1.718} & \multicolumn{2}{|c|}{0.903} & \multicolumn{2}{|c|}{0.969} \\
\hline & \multicolumn{6}{|c|}{$\bar{p}_{l}(y) Q_{l}(y) / \bar{p}_{h}(y) Q_{h}(y)$} \\
\hline & \multicolumn{2}{|c|}{$a f$} & \multicolumn{2}{|c|}{ be } & \multicolumn{2}{|c|}{$c d$} \\
\hline$u=v$ & \multicolumn{2}{|c|}{1.718} & \multicolumn{2}{|c|}{0.903} & \multicolumn{2}{|c|}{0.969} \\
\hline$u=.6, v=.8$ & \multicolumn{2}{|c|}{0.953} & \multicolumn{2}{|c|}{0.650} & \multicolumn{2}{|c|}{0.969} \\
\hline$u=.8, v=.6$ & \multicolumn{2}{|c|}{3.104} & \multicolumn{2}{|c|}{1.153} & \multicolumn{2}{|c|}{0.969} \\
\hline
\end{tabular}

When $u \neq v$, partial evidence acquires a different meaning. When $u=0.6$ and $v=0.8$, the burden is again on the plaintiff. An uninformed plaintiff then 
never sues since he would loose with only partial evidence, but an informed one sues if $x=e$ or $f$. Finally, when $u=0.8$ and $v=0.6$, the burden of proof is on the defendant. When the evidence is mixed, the plaintiff then always sues. If he can, the defendant will then submit counter-evidence if it is in his favor, i.e., when $x=a$ or $b$.

\section{Court Decision-Making}

In the above analysis, society specified at the outset (and committed to) a liability assignment for all possible evidentiary outcomes. How the evidence is interpreted ex post — whether it suggests that the defendant actually caused harm - was not directly relevant. In practice, liability is a matter for courts to decide. Moreover, courts are not provided with a detailed plan of action such as $\psi^{*}$ but must adjudicate, using discretion, on the basis of general legal principles. Since the court decides ex post, what inferences it draws from the evidence then plays a fundamental role.

In this section we discuss how the determination of liability can be delegated to a court, i.e., an adjudicator or judge, now an additional player in the game. Our focus is the design of legal principles or "rules" for court decision-making so as to implement the optimal liability assignment as an equilibrium, using a version of Perfect Bayesian equilibrium. We show that, if courts adjudicate on the basis of the preponderance of evidence standard of proof together with common law exclusionary rules, there exists an equilibrium yielding the optimal liability assignment. Multiple equilibria may nevertheless arise under the same set of rules. Directing courts as to the allocation of the burden of proof is then useful in allowing coordination on the superior equilibrium. An alternative is to let the court itself allocate the burden of proof. We show that this is feasible if the court is given a more "managerial" or "inquisitorial" role, by contrast with that of a passive adjudicator.

We first examine the case of the passive court. The game tree is henceforth 
modified as follows. The initial stage, at which $\psi^{*}$ was announced, disappears. Instead, courts are provided with a set of guiding principles. Moreover, an additional terminal stage is appended at which, if a suit has been filed, the court receives evidence of the form $(y, z), y \in Y, z \in Z(y) \cup\{\phi\}$. Upon receiving that evidence, the court rules whether $D$ caused harm, which by law implies that he is held liable. The court's decision is denoted by $d \in\{0,1\}$, where $d=1$ means that the defendant pays damages and $d=0$ that he does not. If no suit is filed, there is no court action and $D$ does not pay damages.

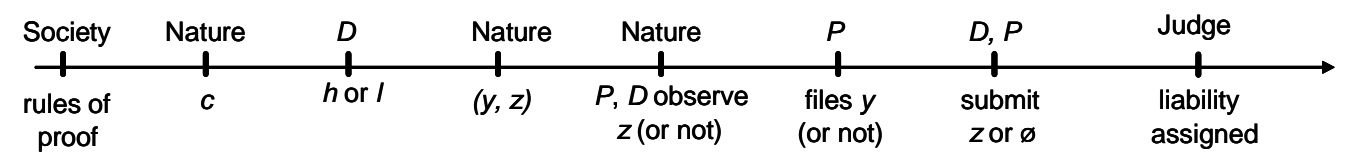

Figure 2: Rules of proof

Thus, the game now includes the players $D, P$ and the court as depicted in figure 2. Everything is assumed to be common knowledge, except $D$ 's cost of care $c$ and his action $j \in\{h, l\}$ which are known only to $D$ (the action may also possibly be known to $P$ ), the partial evidence $y$ which is initially known only to $D$ and $P$, and the additional evidence $z \in Z(y)$ which is initially known only to $D$ and/or $P$ if they are informed. A party does not know whether the other party observed the additional evidence, neither does the court know whether parties are informed. As before, it is common knowledge that $P$ suffers a loss of amount $L$ when $D$ takes action $l$. Hence, the court's role is only to assess whether $D$ 's action was $h$ or $l$.

The complete description of the game requires a specification of the court's "utility function". The latter will follow from the rules of proof, as discussed below. The issue is whether, by maximizing its utility, the court is led to assign liability optimally.

\section{Standard of proof and exclusionary rules}

The court is taken to be a perfect agent abiding by the rules that the law imposes upon it. Our first requirement is for the court to decide the contested 
issue on the basis of a "preponderance of evidence", as this standard of proof is usually understood. The defendant should be found to have caused harm if and only if, upon the evidence, the care level $l$ is more probable than $h$. As is well known, this is equivalent to requiring that the court minimizes the probability of error. The requirement therefore endows the court with a utility function defined by the payoffs

$$
\pi(d, j)=\left\{\begin{array}{l}
1 \text { if } d=0 \text { and } j=h \text { or } d=1 \text { and } j=l \\
0 \text { otherwise. }
\end{array}\right.
$$

As tie-breaking rule, when $h$ and $l$ are both equally probable, we take it that the court decides against the plaintiff.

We next consider the equilibrium implications of this utility function. Suppose that the parties anticipate $d(y, z)=\psi^{*}(y, z)$ for all $y \in Y$ and $z \in Z(y) \cup\{\phi\}$. Party D's choice of care level, party P's decision to file suit and the outcome of the disclosure game are then the same as before. Denote by $S_{j}(y, z)$ the equilibrium probability of the outcome "suit is filed and court receives evidence $(y, z)$ ", conditional on care level $j$ having been exerted.

For the case where $z \in Z(y)$, we have

$$
S_{j}(y, z)=\left\{\begin{array}{l}
u p_{j}(y, z) \text { if } \psi^{*}(y, z)=0, \psi^{*}(y, \phi)=1 \\
v p_{j}(y, z) \text { if } \psi^{*}(y, z)=1, \psi^{*}(y, \phi)=0 \\
0 \text { otherwise, where } y \in Y, z \in Z(y), j=h, l
\end{array}\right.
$$

If $\psi^{*}(y, \phi)=1$, the plaintiff sues on the basis of $y$ and has no incentive to submit further evidence; the defendant submits $z$ if he is informed and the additional evidence satisfies $\psi^{*}(y, z)=0$. The probability for the court to observe $(y, z)$ satisfying the conditions of the top entry is therefore $u p_{j}(y, z)$. When the evidence satisfies the conditions of the middle entry, the plaintiff cannot prevail under $y$ alone. He then sues only if informed and if $\psi^{*}(y, z)=1$, hence the probability $v p_{j}(y, z)$ that such evidence is submitted. In all other cases, the event "suit is filed and court receives evidence $(y, z)$ " is out-of-equilibrium and its probability is therefore nil. The event is 
out-of-equilibrium either because the plaintiff does not sue or because such a combination of the complete evidence is never submitted when a suit is filed.

Bayesian up-dating along the equilibrium path (that is, when $S_{j}(y, z)>0$ for $j=h$ or $j=l$ or both ${ }^{13}$ ) implies that, given the complete evidence, the court's posterior probability about the defendant's action is

$$
\begin{aligned}
\mu(j \mid y, z) & =\frac{\mu_{j}^{0} S_{j}(y, z)}{\mu_{h}^{0} S_{h}(y, z)+\mu_{l}^{0} S_{l}(y, z)} \\
& =\frac{\mu_{j}^{0} p_{j}(y, z)}{\mu_{h}^{0} p_{h}(y, z)+\mu_{l}^{0} p_{l}(y, z)}, \quad j=h, l ; z \in Z(y),
\end{aligned}
$$

where the second equality follows from (6) and where $\mu_{h}^{0}, \mu_{l}^{0}=1-\mu_{h}^{0}$ denote the court's priors at the start of the proceedings. Under the preponderance standard (equivalently, when the court maximizes its expected utility), the defendant is held liable if $\mu(l \mid y, z)>\mu(h \mid y, z)$, that is if

$$
\mu_{l}^{0} p_{l}(y, z)>\mu_{h}^{0} p_{h}(y, z)
$$

Recall that the optimal mechanism generates the deterrence level $\delta^{*}$. Given the distribution function $G$ over the cost of care, this translates into a probability $G\left(L \delta^{*}\right)$ that the defendant exerted care. Thus, in equation (7), a Bayesian court would use $\mu_{h}^{0}=G\left(L \delta^{*}\right)$. Obviously, except nongenerically, a court adjudicating according to (8) will then not implement the optimal liability assignment, which requires the decision $d(y, z)=1$ if $p_{l}(y, z)>p_{h}(y, z)$.

Thus, the preponderance standard does not yield the appropriate outcome. We therefore consider imposing an additional requirement upon court decision-making. This takes the form of "evidentiary rules". We ask the court to abstract from its knowledge of the cost distribution $G$ and to approach the case with "normative" priors $\mu_{h}^{0}=\mu_{l}^{0}=\frac{1}{2}$. The interpretation, quoting Posner (1999), is that "we want the trier of fact to work with prior odds of 1 to 1 ... that the plaintiff has a meritorious case". To illustrate, the

\footnotetext{
${ }^{13}$ By assumption, $p_{h}(y, z)+p_{l}(y, z)>0$ for all $y \in Y, z \in Z(y)$. Hence, when the conditions in the top or middle entry of (6) hold, $S_{j}>0$ for $j=h$ or $j=l$ (or both).
} 
court should put on an "equal" footing defendants drawn from two populations differing by the cost distribution $G$, hence differing in the actual "prior" probability of having caused harm. In other words, courts should disregard as inadmissible information pertaining to the defendants' reputation for behaving a certain way or to their propensity to act negligently. We refer to the standard of proof and evidentiary rules as the rules of proof.

Clearly, a court abiding by the rules of proof does not minimize the actual probability of error. ${ }^{14}$ Rather, it is as if it sought to minimize error from the perspective of an agent holding neutral priors about the individual case upon which it has to decide. Observe that this provides a way out of such classic conundrums as the "bus case" and the "gate crasher's paradox". In the latter, 600 of the 1000 people in the audience of a rock concert crashed the gate and did not pay the ticket. Assuming all legitimate ticket stubs have been lost, should someone picked at random in the audience be held liable, given that there is a $60 \%$ chance that he was a gate crasher? According to the rules of proof described above, "naked" statistical evidence pertaining to $G(\cdot)$ should simply not be considered.

Proposition 3 The optimal liability assignment $d(y, z)=\psi^{*}(y, z), y \in Y$, $z \in Z(y) \cup\{\phi\}$, is part of an equilibrium with court decision-making constrained by the rules of proof.

Up to this point we have shown that, under the rules of proof, the court's decision is consistent with the optimal mechanism when the whole potential evidence is received. To complete the proof of proposition 3, it remains to show that this is also true when the evidence is $(y, \phi)$ at the close of the proceedings.

In equilibrium, such an outcome occurs only if $\psi^{*}(y, \phi)=1$ and the defendant is either uninformed of the true $z$ or gains nothing by submitting

\footnotetext{
${ }^{14}$ This contrasts with the justification of the preponderance standard that prevails in the legal literature (e.g., Sherwin and Clermont, 2002). In a related model, Fluet (2003) compares the ex ante incentives to exert care under truth-seeking courts versus courts abiding by the rules of proof.
} 
the additional evidence because $\psi^{*}(y, z)=1$ as well. When $\psi^{*}(y, \phi)=0$, the outcome $(y, \phi)$ is not part of the equilibrium because an uninformed plaintiff does not sue. Taking the above into consideration, the probability of "suit is filed and evidence is $(y, \phi)$ ", conditional on the level of care, is therefore

$$
S_{j}(y, \phi)=\left\{\begin{array}{l}
\bar{p}_{j}(y)\left[1-u+u \sum_{z \in Z(y)} \psi^{*}(y, z) p_{j}(z \mid y)\right] \text { if } \psi^{*}(y, \phi)=1 \\
0 \text { otherwise, where } y \in Y, j=h, l
\end{array}\right.
$$

Along the equilibrium path, using the court's "normative priors", the posterior probabilities about the defendant's action are then

$$
\mu(j \mid y, \phi)=\frac{\left(\frac{1}{2}\right) S_{j}(y, \phi)}{\left(\frac{1}{2}\right) S_{h}(y, \phi)+\left(\frac{1}{2}\right) S_{l}(y, \phi)}, \quad j=h, l .
$$

Hence, $\mu(l \mid y, \phi)>\mu(h \mid y, \phi)$ and therefore $d(y, \phi)=1$ if $S_{l}(y, \phi)>$ $S_{h}(y, \phi)$. We now show that the latter holds along the equilibrium path. For this purpose, observe that $Q_{j}(y)$ in proposition 2 can be rewritten as

$$
Q_{j}(y)=1-u+(u-v) \sum_{z \in Z(y)} \psi^{*}(y, z) p_{j}(z \mid y) .
$$

Substituting in (9), we get

$$
S_{j}(y, \phi)=\bar{p}_{j}(y)\left[Q_{j}(y)+v \sum_{z \in Z(y)} \psi^{*}(y, z) p_{j}(z \mid y)\right], \quad j=h, l .
$$

Therefore,

$$
\begin{aligned}
S_{l}(y, \phi)- & S_{h}(y, \phi)=\left[\bar{p}_{l}(y) Q_{l}(y)-\bar{p}_{h}(y) Q_{h}(y)\right] \\
& +v \sum_{z \in Z(y)} \psi^{*}(y, z)\left[p_{l}(y, z)-p_{h}(y, z)\right]>0 .
\end{aligned}
$$

The sign follows whenever $\psi^{*}(y, \phi)=1$, i.e. along the equilibrium path. To see this, observe that by proposition 2 , the first bracket on the right-hand-side is then positive. Moreover, by proposition 1, the second expression is always nonnegative. Altogether, along the equilibrium path, the court's decisions under the rules of proof implement the optimal liability assignment. In the appendix we discuss out-of-equilibrium beliefs that sustain the equilibrium. 


\section{Multiple equilibria}

The foregoing analysis showed that the optimal liability assignment is consistent with courts operating on the basis of the preponderance standard and exclusionary rules. Note that the discussion did not refer to the allocation of the burden of proof, although section 4 showed that the optimal mechanism entails a burden of proof assignment. Under the rules of proof, the appropriate allocation of the burden arose "spontaneously" in the form of presumptions in favor of or against the defendant. Indeed, the argument was that, if the parties' file and disclosure strategies were the same as under the mechanism $\psi^{*}$, then the court's best reply would be $d=\psi^{*}$, thereby sustaining the optimal liability assignment as an equilibrium. However, this leaves open the possibility that there are other equilibria, possibly inefficient ones, that are also consistent with the same rules of proof. Specifically, if the parties choose their actions under the belief that the court's strategy is $d(y, \phi) \neq \psi^{*}(y, \phi)$, can $d(y, \phi)$ be a best reply for the court?

We illustrate this possibility with the example in Table 1. Recall from section 4 that a party was said to bear the burden of proof if he is the only party with a possible incentive to submit $z$. In the optimal mechanism for the example of table 1 , the defendant bears the burden when $u=.8$ and $v=.6$; he is then always held liable when the partial evidence is mixed, which is when $y$ is either af or be. By contrast, the plaintiff bears the burden when $u=.6$ and $v=.8$, since mixed evidence is then not sufficient for the plaintiff to win.

Table 2 reproduces the optimal $\psi^{*}(y, \phi)$ for these two cases. The strategy $d(y, \phi)$, which allocates the burden of proof differently, is also part of a sequential equilibrium consistent with the rules of proof. The table gives $d(y, \phi)$ only for mixed evidence; in all other cases the court's decision is the same as $\psi^{*}$. 
Table 2: Inefficient Equilibria

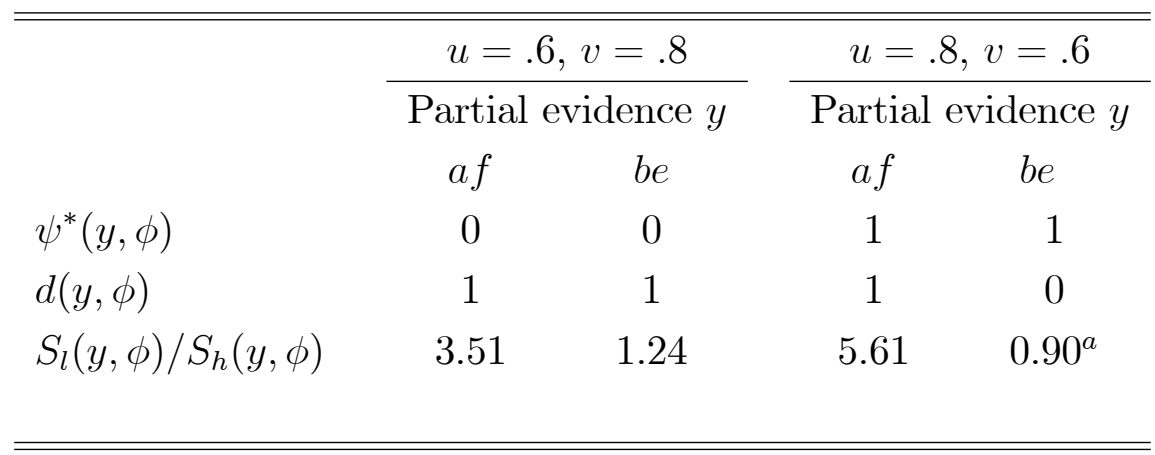

${ }^{a}$ Out of equilibrium, as described in the text.

To see that $d(y, \phi)$ as shown is part of an equilibrium, consider first the case $u=.6, v=.8$. In contrast to the optimal liability assignment, it is now as if the court had a presumption against the defendant. The plaintiff therefore always sues when the evidence is mixed and he never submits $z$. Since the plaintiff wins under $(y, \phi)$, the probability $S_{j}(y, \phi)$ is as defined in equation (9) but with $d(y, \phi)$ substituted for $\psi^{*}(y, \phi)$. Using the figures in table 1 , this yields $S_{l}(y, \phi)>S_{h}(y, \phi)$. Holding the defendant liable is therefore warranted under the rules of proof.

When $u=.8$ and $v=.6$, the liability assignment under the optimal mechanism is for the defendant to bear the burden of proof. However, in the equilibrium represented in table 2 , the defendant prevails when the partial evidence is be. His best response is therefore to remain passive should a suit be filed. Accordingly, an uninformed plaintiff does not sue when the partial evidence is be since he has nothing to gain (an informed plaintiff would sue only if the complete evidence is $e$ ). Given the court's strategy, the event "suit is filed and evidentiary outcome is be" is clearly out of equilibrium. In the table, $S_{l}(b e, \phi) / S_{h}(b e, \phi)$ is derived under the out-of-equilibrium beliefs that an uninformed plaintiff sues by mistake with probability $\varepsilon$. Hence, conditional on the level of care, the evidence be is presented to the court with probability $(1-v) \bar{p}_{j}(b e) \varepsilon$. This leads to the posterior odds in table 
$2 .{ }^{15}$ Thus, under the rules of proof, the defendant is not held liable, which sustains the equilibrium.

In both cases, the intuition is the same. An equilibrium is based on selfsustaining presumptions. These affect equilibrium strategies, which in turn affect the inferences that can be drawn from the evidence. Hence, multiple equilibria are possible under the same rules of proof. In the example, all the equilibria are equally reasonable. In fact, the multiplicity of equilibria illustrated in the example is generic, as shown by the next proposition.

Proposition 4 Under the rules of proof, there are multiple equilibria if $u$ and $v$ are sufficiently large. For any $y \in Y$ constituting mixed evidence, $d(y, \phi)=1$ is part of one equilibrium and $d(y, \phi)=0$ of another.

When $u$ and $v$ are small, the court's assessment is essentially determined by whether $\bar{p}_{l}(y)$ is greater or less than $\bar{p}_{h}(y)$. The "naive" information content of $y$ dominates since the parties are relatively unlikely to possess additional information. Hence, the equilibrium is unique. By contrast, when $u$ and $v$ are large, the interpretation of $(y, \phi)$ is equilibrium determined, hence the existence of multiple equilibria.

\section{Burden of proof and active judges}

This suggests a role for additional judicial tools in order to help select the right equilibrium. One possibility is to provide courts with guidelines regarding the allocation of the burden of proof. For instance, suppose there is a category of cases corresponding to $u=.6$ and $v=.8$. For this category, courts could be instructed to let the plaintiffs bear the burden.

\footnotetext{
${ }^{15}$ These are the same as the "uncorrected" odds in table 1 . There are other possibilities. The court could rationalize the out-of-equilibrium outcome as a suit by either an uninformed plaintiff or an informed one with unfavorable evidence. This would lead to even smaller posterior odds $S_{l} / S_{h}$. The equilibrium is sustained as long as the court does not put too much weight on the possibility that an informed plaintiff sued on the basis of favorable complete evidence, but then "forgot" to submit $z$.
} 
An interpretation is that courts are then required to use a specific presumption. In terms of the model, the guideline could also be interpreted as a statement to the effect that a plaintiff can prevail only if he also submits the second "file" (which contains $z$ ). This amounts to specifying the type of evidence required to win a suit, i.e., it characterizes the necessary conditions for a "proof". Such guidelines could be imposed through statute law or follow from rulings by higher jurisdictions. They could also derive from custom or general jurisprudence. Whatever the means, the important point is that the burden assignment does not follow from the rules of proof alone at the trial court level. Obviously, burden of proof guidelines must apply to large classes of cases, irrespective of the detailed information only available at the court level. In general, they will therefore not be sufficient to ensure coordination on the efficient equilibrium.

In the remainder we consider another possibility. So far, our stylized court procedure involved a purely "passive" adjudicator whose only role is to decide at the close of the proceedings, once the parties have presented evidence favouring their case. We now allow the adjudicator to intervene during the proceedings, as in the more inquisitorial procedure of civil law countries. By contrast with a purely adversarial (i.e., party controlled) procedure, where the judge sits as a silent referee, the "inquisitorial judge" interrogates the parties or witnesses directly and may purposely shift the burden of proof. In civil litigation, the more or less active role of the judge is one of the main differences between the common law and civil law procedures, since most if not all of the evidence is supplied by the parties in both systems.

We model the active court as follows. As before, the court's decision is $d(y, z)$, for $y \in Y$ and $z \in Z(y) \cup\{\phi\}$, at the close of the proceedings. However, the game is augmented to include an intermediate stage, after the plaintiff's decision to file suit and the presentation of $y$ and before the potential disclosure of additional evidence. At this intermediate stage, the judge interrogates the parties for possible additional evidence and may suggest how he would rule on the basis of the evidence presented so far. Formally, the 
judge makes an announcement $b \in\{0,1\}$, where $b=1$ means "sufficient", i.e., it conveys that the plaintiff will prevail on the basis of the evidence $y$ alone unless additional evidence is brought forward by the defendant. In other words, $b=1$ suggests that the burden of proof is on the defendant and is equivalent to interrogating the defendant under the threat of adjudicating against him. Conversely, $b=0$ means "insufficient" and suggests that the burden of proof is still on the plaintiff. The figures 3 and 4 emphasize the difference between burden of proof guidelines imposed "from above" and burden of proof shifts through announcements at the trial court level.

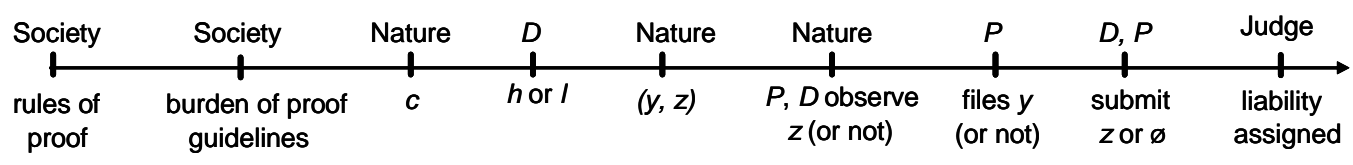

Figure 3: Burden of proof guidelines

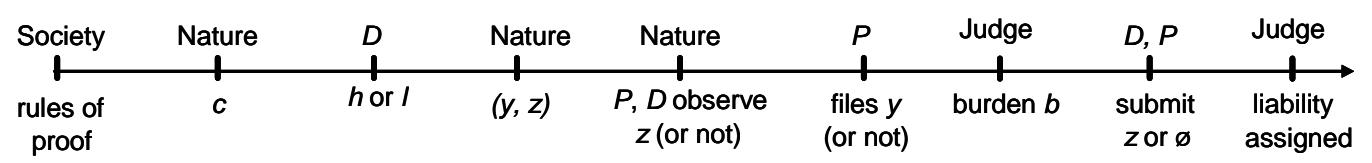

Figure 4: Active adjudicator

We first consider the case where announcements are binding. To illustrate, in German civil procedure, the judge may inform a party that, unless he presents some additional more convincing evidence, the court is likely to rule a certain way. Such a "judicial advice" is written to the protocol of the proceeding, which in general would make it difficult for a judge not to follow through (otherwise a mislead party would have ground for appeal). ${ }^{16}$ We show that, if judicial announcements are binding and the judge otherwise abides by the rules of proof, there is a unique equilibrium characterized by

\footnotetext{
${ }^{16}$ The practice of "richterliche Hinweis" is described in Zivilprozessordnung, article 139.
} 
the optimal liability assignment. We next consider non binding announcements. The communication stage is then purely rhetorical, involving cheap talk. We show that the same results nevertheless follow if one assumes that "credible" announcements are believed by the parties.

Denote by $b(y)$ the judge's announcement strategy, i.e., the announcement at the information set where a suit has been filed and he partial evidence is $y$. When announcement are binding, decisions at the terminal adjudication stage are constrained by $d(y, \phi)=b(y)$. We have the following result.

Proposition 5 If the judge's announcements are binding, the equilibrium is unique and the judge's strategy under the rules of proof satisfies $b(y)=$ $\psi^{*}(y, \phi), d(y, \phi)=b(y), d(y, z)=\psi^{*}(y, z), y \in Y, z \in Z(y)$.

Given the rules of proof, the judge and the parties know that $d(y, z)=$ $\psi^{*}(y, z)$ will be chosen if the complete evidence is disclosed. Faced with a binding announcement, the parties have dominant strategies regarding disclosure. Anticipating the parties' response, the judge therefore chooses $b$ to maximize his expected payoff (the probability of not making "mistakes"), using the "normative" priors about the defendant's care level and conditionally on his beliefs at the information set $y$. These beliefs do not depend on the parties's strategies, hence the equilibrium is unique.

We now extend the analysis to non binding announcements. As is well known from the cheap talk literature, there always exists an equilibrium where costless statements are considered to be meaningless. In the present context, this would mean that the outcome of the game with inquisitorial judge is the same as with a passive adjudicator. In what follows, we select equilibria satisfying the condition that credible statements about planned behavior are believed. Standard requirements for credibility are that announcements be self-committing and self-signalling (see for instance Farrell and Rabin, 1996).

Consider the first requirement. At the information set $y$, the announcement $b$ is self-committing when $d(y, \phi)=b$ is the judge's best response at 
the adjudication stage, if he expects the announcement to be believed. This requires that $d(y, \phi)$ be part of an equilibrium. From proposition 3, it follows that the announcement $b=\psi^{*}(y, \phi)$ is self-committing. In particular, when the game with passive adjudicator has a unique equilibrium, then the only credible announcements are those which yield the optimal liability assignment. However, from proposition 4, we know that there are cases where $d(y, \phi) \neq \psi^{*}(y, \phi)$ is also part of an equilibrium. Hence, an announcement $b^{\prime} \neq \psi^{*}(y, \phi)$ would also be self-committing, although by proposition 5 the judge would prefer to announce $b$ and carry out his plan if he expected $b$ to be believed.

However, a judge announcing $b$ may still be tempted to adjudicate according to $b^{\prime}$ if he thinks the announcement of $b$ will not be believed. In particular, a difficulty arises if the payoff from adjudicating according to $b^{\prime}$ is greater when the parties play under the belief that the judge will stick to $b$. Knowing this, it could be rational for the parties not to believe $b$. The selfsignalling requirement is an additional condition ruling out this difficulty. ${ }^{17}$ Announcements are self-signalling if the judge would not want the parties to believe he will play some $b^{\prime \prime}$ if he intends to play otherwise, i.e., if he has no incentive to be misleading about his intentions, whatever these are. We show that this requirement is satisfied.

Lemma 2 The judge's announcements of $d(y, \phi)$ are self-signalling.

Given the self-signalling property, self-committing announcements should therefore be believed. The next result then follows directly from proposition 5 .

Proposition 6 Under the rules of proof, $d(y, z)=\psi^{*}(y, z), y \in Y, z \in$ $Z(y) \cup\{\phi\}$, is part of the unique equilibrium satisfying the condition that credible announcements are believed.

\footnotetext{
${ }^{17}$ The condition is due to Aumann (1990). Baliga and Morris (2002) provide an illuminating discussion of the two conditions.
} 


\section{Related literature and conclusions}

Posner (1999) remarked that the economic literature on the law of evidence is scanty in relation to its scope and importance. While there is an already vast literature on litigation, the legal principles constraining court decisionmaking have been little discussed from the usual standpoint of law and economics. Our contribution has been to provide a simple model to analyze some of the basic issues concerning rules of proof and procedures. We summarize our main results, relate them to the literature and suggest possible extensions.

It has been emphasized elsewhere (in particular Daughety and Reinganum 2000a, 2000b) that the trial process cannot be purely Bayesian due to evidentiary rules and other features of the procedure. It has also often been noted that it may be useful to commit Bayesian decision-makers to rules that may not be optimal ex post from an error-minimizing perspective (e.g., Schrag and Scotchmer 1994, Daughety and Reinganum 1995, Lewis and Poitevin 1997, Sanchirico 2001b, Bernhardt and Nosal 2004). We showed that, if the purpose of tort law is deterrence, the preponderance standard and the usual exclusionary rules under common law are efficient. An extension would be to dwell deeper into the characterization of courts as "constrained-Bayesians" and consider rules of proof in more complex litigation.

The trial was modelled as a persuasion game in the manner of Milgrom and Roberts (1986), assuming that the extent of the interested parties' information is not verifiable, as in Shin (1998). One difference with the latter is that there are typically multiple equilibria in our set-up, which explains the need for burden of proof guidelines or for a more active judge. Multiple equilibria arise non trivially because of our assumption that presenting evidence is costly, so that parties have no incentives to submit favorable evidence unless it strictly improves their prospects. Similar results were also obtained by Sobel (1985) in a model where proofs are costly. We showed that an active judge, operating under common law rules of proof, would allocate the burden of proof efficiently. Even if burden of proof announcements are not 
binding, the active judge can elicit efficient disclosure by credibly threatening the parties to adjudicate a certain way.

These results shed light on the adversarial versus inquisitorial controversy. The distinction refers to the role of the judge versus the parties' in the factfinding phase of the trial, with common law on the one hand and civil law on the other. In the economic literature, "inquisitorial" has usually been assimilated to a procedure where a disinterested investigator (e.g., a public official) is responsible for discovery, as opposed to the adversarial method where the parties have full control over the uncovering and presentation of evidence (see Shin 1998, Dewatripont and Tirole 1999, Froeb and Kobayashi 2001, Palumbo 2001). ${ }^{18}$ However, as far as civil litigation is concerned and by contrast with criminal trials, the presentation of proof is mainly the parties' responsibility even in the civil law system.

While the civil law judge may investigate facts on his own initiative (e.g., through court-appointed experts), the main practical difference is the judge's greater direct involvement in guiding the litigants' submission of evidence through bench request, questions and suggestions (Parisi, 2002, provides a short comparative description). This is not unlike "managerial judging" in the US discovery process, in the sense that it may focus discovery (and prevent excesses, see Schrag 1999), but it does also allow the use of hints or threats, implicit or explicit, as to how the judge will adjudicate on the basis of the evidence presented so far. If the extent of the parties' information is unverifiable, such threats may be the only means available to elicit disclosure. Our analysis provides a rationale for a procedure with an active judge. ${ }^{19}$

\footnotetext{
${ }^{18}$ One exception is Block and Parker's (2004) experimental study of the efficiency of adjudication with a passive referre as opposed to an active one who is the only questioner permitted. They interpret their findings as suggesting the need for burden of proof guidelines in the purely adversarial procedure.

${ }^{19}$ Actual systems range on a scale from the theoretically pure adversarial to the theoretically pure inquisitorial (see Jolowicz, 2000, 2003). For instance, article 32.1 of England' new Civil Procedure Rules allows the court much power in controlling evidence. Similarly, under Rule 614(b) of the Federal Rules of Evidence, U.S. federal courts may in principle interrogate and even call witnesses, although in practice this is unusual. On the
} 
Our results would be affected if society is also concerned with the costs of presenting evidence. Bernardo, Talley and Welch (2000) analyzed the tradeoff between deterrence and litigation costs (see also Rubinfeld and Sappington, 1987). A similar concern in our model would seem to justify a more stringent standard of proof than preponderance. This would yield less deterrence but would also reduce the frequency of suits, and thereby litigation costs, by making it more difficult for a plaintiff to prevail. A concern for costs would also impact on the allocation of the burden of proof if parties differ in the cost of presenting the "additional" evidence, i.e., there would now be a tendency to put the burden on the cheaper information provider (see Hay and Spier, 1997), although taking into account the likelihood that the litigants have access to evidence. This would affect disclosure, hence deterrence.

However, changes in the standard of proof and in the allocation of the burden of proof interact in complex ways. Allocating the burden of proof to the defendant because he is the cheaper information provider could stimulate suits. Moreover, if the defendant is allocated the burden of proof for cost reasons, must he meet the same higher standard of proof to discharge it, which would also stimulate suits? Whether reasonably simple general rules of proof can be obtained in this context is doubtful but merits future research.

We abstracted from many other relevant considerations. For instance, our litigants were endowed with hard evidence. Their strategies would be different if they had to invest to uncover evidence. How does this impact on the efficient standard of proof and burden assignment? We also abstracted from the possibility of out-of-court settlements. Again, this is an avenue for future research.

other hand, judicial or statutory decisions in most U.S. states have explicitly restricted the judge's power to comment on the evidence. 


\section{Appendix}

Proof of proposition 2: We first justify the expression for $e_{j}(y)$ in (2). Let $Z^{+}(y) \subset Z(y)$ be the set of $z$ 's such that $\psi(y, z)>\psi(y, \phi)$. Similarly, let $Z^{-}(y) \subset Z(y)$ be the set of $z^{\prime}$ 's such that $\psi(y, z)<\psi(y, \phi)$. An informed plaintiff submits $z$ only if $z \in Z^{+}(y)$; an informed defendant submits $z$ only if $z \in Z^{-}(y)$. Then

$$
\begin{aligned}
e_{j}(y)= & \left(1-v \sum_{z \in Z^{+}(y)} p_{j}(z \mid y)-u \sum_{z \in Z^{-}(y)} p_{j}(z \mid y)\right) \psi(y, \phi) \\
& +v \sum_{z \in Z^{+}(y)} p_{j}(z \mid y) \psi(y, z)+u \sum_{z \in Z^{-}(y)} p_{j}(z \mid y) \psi(y, z) .
\end{aligned}
$$

To see this, note that the expression in the right-hand side parenthesis equals

$$
\begin{aligned}
\left(1-\sum_{z \in Z^{+}(y)} p_{j}(z \mid y)\right. & \left.-\sum_{z \in Z^{-}(y)} p_{j}(z \mid y)\right) \\
& +(1-v) \sum_{z \in Z^{+}(y)} p_{j}(z \mid y)+(1-u) \sum_{z \in Z^{-}(y)} p_{j}(z \mid y) .
\end{aligned}
$$

This is the probability that additional evidence will not change the probability of liability compared to $\psi(y, \phi)$, plus the probability that it would have but the interested party was uninformed. Hence, it is the probability of "no change". The second term in (11) is the probability that the plaintiff is informed times the expected probability of liability for $z \in Z^{+}(y)$. A similar interpretation holds for the third term.

Expression (11) can be rewritten as

$$
\begin{array}{r}
e_{j}(y)=\psi(y, \phi)+v \sum_{z \in Z^{+}(y)} p_{j}(z \mid y) \psi(y, z)[\psi(y, z)-\psi(y, \phi)] \\
-u \sum_{z \in Z^{-}(y)} p_{j}(z \mid y)[\psi(y, \phi)-\psi(y, z)]
\end{array}
$$


which explains (2).

The optimal $\psi$ maximizes deterrence defined as

$$
\begin{aligned}
\delta= & \sum_{y \in Y}\left[\bar{p}_{l}(y) e_{l}(y)-\bar{p}_{h}(y) e_{h}(y)\right] \\
= & \sum_{y \in Y}\left[\bar{p}_{l}(y)-\bar{p}_{h}(y)\right] \psi(y, \phi) \\
& +\sum_{y \in Y} \sum_{z \in Z(y)}\left[p_{l}(y, z)-p_{h}(y, z)\right] \tau(y, z),
\end{aligned}
$$

where we substituted for $e_{j}(y)$ from (2) and where

$$
\tau(y, z)=v \max [0, \psi(y, z)-\psi(y, \phi)]-u \max [0, \psi(y, \phi)-\psi(y, z)]
$$

The second term in (12) is maximized if $\tau(y, z)$ is as large as possible when $p_{l}(y, z)>p_{h}(y, z)$ and as small as possible when $p_{l}(y, z)<p_{h}(y, z)$. Taking $\psi(y, \phi)$ as given, this implies

$$
\psi(y, z)=\left\{\begin{array}{lll}
1 & \text { when } \quad p_{l}(y, z)>p_{h}(y, z) \\
0 & \text { when } \quad p_{l}(y, z)<p_{h}(y, z) .
\end{array}\right.
$$

Thus, $\psi(y, z)=\psi^{*}(y, z)$ for $z \in Z(y)$, which proves the first claim in the proposition. Substituting this result in (13) and from the latter in (12) yields

$$
\begin{aligned}
\delta= & \sum_{y \in Y}\left[\bar{p}_{l}(y)-\bar{p}_{h}(y)\right] \psi(y, \phi) \\
& +\sum_{y \in Y} \sum_{z \in Z(y)}\left[p_{l}(y, z)-p_{h}(y, z)\right] v \psi^{*}(y, z)(1-\psi(y, \phi)) \\
& -\sum_{y \in Y} \sum_{z \in Z(y)}\left[p_{l}(y, z)-p_{h}(y, z)\right] u\left(1-\psi^{*}(y, z)\right) \psi(y, \phi) \\
= & v \sum_{y \in Y} \sum_{z \in Z(y)}\left[p_{l}(y, z)-p_{h}(y, z)\right] \psi^{*}(y, z) \\
& +\sum_{y \in Y}\left[\bar{p}_{l}(y) Q_{l}(y)-\bar{p}_{h}(y) Q_{h}(y)\right] \psi(y, \phi),
\end{aligned}
$$


where

$$
Q_{j}(y)=1-v \sum_{z \in Z(y)} \psi^{*}(y, z) p_{j}(z \mid y)-u \sum_{z \in Z(y)}\left[1-\psi^{*}(y, z)\right] p_{j}(z \mid y)
$$

or equivalently

$$
\begin{aligned}
Q_{j}(y)=(1-v)(1-u)+(1-u) v \sum_{z \in Z(y)}\left[1-\psi^{*}(y, z)\right] p_{j}(z \mid y) \\
+(1-v) u \sum_{z \in Z(y)} \psi^{*}(y, z) p_{j}(z \mid y) .
\end{aligned}
$$

Choosing $\psi(y, \phi)$ to maximize the second term in (14) implies

$$
\psi^{*}(y, \phi)= \begin{cases}1 & \text { when } \bar{p}_{l}(y) Q_{l}(y)>\bar{p}_{h}(y) Q_{h}(y), \\ 0 & \text { when } \bar{p}_{l}(y) Q_{l}(y)<\bar{p}_{h}(y) Q_{h}(y),\end{cases}
$$

thereby proving the second claim.

Proof of corollary 2: The optimal scheme assigns liability according to the sign of

$$
\eta(y):=\bar{p}_{l}(y) Q_{l}(y)-\bar{p}_{h}(y) Q_{h}(y)=(1-v) \mu^{+}(y)+(1-u) \mu^{-}(y)
$$

where

$$
\begin{gathered}
\mu^{+}(y):=\sum_{z \in Z(y)} \psi^{*}(y, z)\left[p_{l}(y, z)-p_{h}(y, z)\right]>0, \\
\mu^{-}(y):=\sum_{z \in Z(y)}\left[1-\psi^{*}(y, z)\right]\left[p_{l}(y, z)-p_{h}(y, z)\right] \leq 0,
\end{gathered}
$$

and where the sign follows from proposition 2 and the assumption that $y$ is mixed. To prove the first part of the corollary, recall that the burden is on the defendant if $\eta(y)>0$. Now, $\eta(y)>0$ when $v<u=1$. By continuity, it follows that there exists $u_{c} \in(v, 1)$ such that $\eta(y)>0$ if $u \geq u_{c}$. The proof of the second part is similar provided $\mu^{-}(y)<0$, which obtains if there exists $z \in Z(y)$ such that $p_{l}(y, z)<p_{h}(y, z)$. 
Proof of proposition 3: We complete the argument in the text by specifying out-of-equilibrium beliefs. These are non trivial only when the evidence is incomplete and such that $\psi^{*}(y, \phi)=0$, which can only result from the plaintiff deviating from his equilibrium strategy (the defendant's equilibrium strategy is to remain passive when such a $y$ is submitted). There are three possibilities: the plaintiff was uninformed but nevertheless sued on the basis of $y$ alone; he was informed, but $\psi^{*}(y, z)=0$ and he nevertheless sued, disclosing only $y$; he was informed and $\psi^{*}(y, z)=1$, hence he should have sued as prescribed by the equilibrium but then "forgot" to also submit $z$. Outof-equilibrium beliefs sustain the equilibrium if they put a sufficiently small weight on the third possibility. For instance, put zero weight on the third possibility and an equal weight on the first two with, say, an $\varepsilon$ probability of mistake on the part of the plaintiff. The probability of $(y, \phi)$, conditional on the care level, is then

$$
\begin{aligned}
s_{j} & \equiv \bar{p}_{j}(y)\left[1-v+v \sum_{z \in Z(y)}\left(1-\psi^{*}(y, z)\right) p_{j}(z \mid y)\right] \varepsilon \\
& =\bar{p}_{j}(y)\left[Q_{j}(y)+u \sum_{z \in Z(y)}\left(1-\psi^{*}(y, z)\right) p_{j}(z \mid y)\right] \varepsilon, \quad j=h, l .
\end{aligned}
$$

Hence,

$$
\begin{gathered}
\frac{s_{l}-s_{h}}{\varepsilon}=\left[\bar{p}_{l}(y) Q_{l}(y)-\bar{p}_{h}(y) Q_{h}(y)\right] \\
+u \sum_{z \in Z(y)}\left(1-\psi^{*}(y, z)\right)\left[p_{l}(y, z)-p_{h}(y, z)\right] \leq 0 .
\end{gathered}
$$

By proposition 2, the expression in the first bracket is nonpositive when $\psi^{*}(y, \phi)=0$. By proposition 1 , the second term on the right-hand-side is also non positive. Thus, the defendant is not held liable under the preponderance standard, as required to sustain the equilibrium.

Proof of proposition 4: By proposition 3, $d(y, \phi)=\psi^{*}(y, \phi)$ is part of an equilibrium. We show that $d(y, \phi)=1$ is also part of an equilibrium when 
$\psi^{*}(y, \phi)=0$, provided $u$ or $v$ are sufficiently large. A similar argument would show that $d(y, \phi)=0$ is part of an equilibrium when $\psi^{*}(y, \phi)=1$.

By proposition $2, \psi^{*}(y, \phi)=0$ if $\bar{p}_{l}(y) Q_{l}(y) \leq \bar{p}_{h}(y) Q_{h}(y)$ or equivalently

$$
(u-v) \sum_{z \in Z(y)} \psi^{*}(y, z)\left[p_{l}(y, z)-p_{h}(y, z)\right] \leq(1-u)\left[\bar{p}_{h}(y)-\bar{p}_{l}(y)\right] .
$$

From the discussion in the text and using (9), the strategy $d(y, \phi)=1$ is part of an equilibrium if

$$
\begin{aligned}
& \bar{p}_{l}(y)\left[1-u+u \sum_{z \in Z(y)} \psi^{*}(y, z) p_{l}(z \mid y)\right]> \\
& \bar{p}_{h}(y)\left[1-u+u \sum_{z \in Z(y)} \psi^{*}(y, z) p_{h}(z \mid y)\right]
\end{aligned}
$$

or equivalently

$$
u \sum_{z \in Z(y)} \psi^{*}(y, z)\left[p_{l}(y, z)-p_{h}(y, z)\right]>(1-u)\left[\bar{p}_{h}(y)-\bar{p}_{l}(y)\right] .
$$

If $y$ is mixed,

$$
\sum_{z \in Z(y)} \psi^{*}(y, z)\left[p_{l}(y, z)-p_{h}(y, z)\right]>\max \left[0, \bar{p}_{l}(y)-\bar{p}_{h}(y)\right] .
$$

a) Suppose $\bar{p}_{h}(y)>\bar{p}_{l}(y)$. Given (20), the summations on the left-hand side of (18) and (19) are strictly positive. Inequality (19) holds for $u$ sufficiently large, say $u>u^{\prime}$, where $u^{\prime}$ equalizes the left and right-hand side of (19). Inequality (18) holds if $v$ is sufficiently large, say $v \geq v^{\prime}(u)$ where $v^{\prime}(u)<u$ equalizes the left and right-hand side of (18). Hence, $u>u^{\prime}$ and $v \geq v^{\prime}(u)$ imply that $d(y, \phi)=1$ is part of an equilibrium, while $d(y, \phi)=\psi^{*}(y, \phi)=0$ is part of another.

b) Suppose $\bar{p}_{h}(y) \leq \bar{p}_{l}(y)$. Given (20), inequality (19) then holds for any $u$. We show that inequality (18) holds if $v$ is sufficiently large. To see this, multiply both sides of (20) by $u-1$, yielding

$$
(u-1) \sum_{z \in Z(y)} \psi^{*}(y, z)\left[p_{l}(y, z)-p_{h}(y, z)\right]<(1-u)\left[\bar{p}_{h}(y)-\bar{p}_{l}(y)\right] .
$$


This means that (18) holds for $v=1$. By continuity, there exists $v^{\prime}(u) \in(u, 1)$ such that (18) holds if $v \geq v^{\prime}(u)$. Thus, there are multiple equilibria if $v$ is sufficiently large.

Proof of proposition 5: That $d(y, z)=\psi^{*}(y, z)$ for $z \in Z(y)$ follows directly from the rules of proof. If $y$ is conclusive, the judge's best move is obviously $b(y)=\psi^{*}(y, \phi)$ so we consider only instances where $y$ is mixed.

Conditional on the care level $j$, the probability of being at the information set "suit and evidence $y$ " is $\bar{p}_{j}(y) \eta(y)$, where $\eta(y)$ is the conditional probability, over all the plaintiff's types, that a suit is filed. This depends on the equilibrium, but in any case $\eta(y)>0$ when $y$ is mixed (even if he cannot win on the basis of $y$ alone, a plaintiff has a probability $v>0$ of assessing favorable additional evidence). At the information set "suit and evidence $y$ ", using the normative "priors", the judge's up-dated beliefs about $j$ are therefore

$$
\begin{aligned}
\mu(j \mid y) & =\frac{\left(\frac{1}{2}\right) \bar{p}_{j}(y) \eta(y)}{\left(\frac{1}{2}\right) \bar{p}_{h}(y) \eta(y)+\left(\frac{1}{2}\right) \bar{p}_{l}(y) \eta(y)} \\
& =\frac{\bar{p}_{j}(y)}{\bar{p}_{h}(y)+\bar{p}_{l}(y)}, \quad j=h, l .
\end{aligned}
$$

If $b=1$ is announced, the parties' dominant strategies are for the plaintiff not to disclose additional evidence and for the defendant to disclose evidence if informed and the evidence is favorable. The reverse holds if $b=0$ is announced. Given $d(y, z)=\psi^{*}(y, z)$ for $z \in Z(y)$, the judge's expected payoff from $b=1$ is therefore

$$
\begin{aligned}
\bar{\pi}(1, y)= & \mu(h \mid y)\left[u \sum_{z \in Z(y)}\left(1-\psi^{*}(y, z)\right) p_{h}(z \mid y)\right] \\
& +\mu(l \mid y)\left[1-u+u \sum_{z \in Z(y)} \psi^{*}(y, z) p_{l}(z \mid y)\right] .
\end{aligned}
$$

The first square bracket is the probability of decision $d=0$ when $j=h$. The second bracket is the probability of $d=1$ when $j=l$. Similarly, the 
expected payoff from $b=0$ is

$$
\begin{aligned}
\bar{\pi}(0, y)= & \mu(h \mid y)\left[1-v+v \sum_{z \in Z(y)}\left(1-\psi^{*}(y, z)\right) p_{h}(z \mid y)\right] \\
& +\mu(l \mid y)\left[v \sum_{z \in Z(y)} \psi^{*}(y, z) p_{l}(z \mid y)\right] .
\end{aligned}
$$

The judge chooses $b=1$ if

$$
\begin{aligned}
\bar{\pi}(1, y)-\bar{\pi}(0, y)= & \mu(l \mid y)\left[1-u+(u-v) \sum_{z \in Z(y)} \psi^{*}(y, z) p_{l}(z \mid y)\right] \\
& -\mu(h \mid y)\left[1-u+(u-v) \sum_{z \in Z(y)} \psi^{*}(y, z) p_{h}(z \mid y)\right] \\
= & \mu(l \mid y) Q_{l}(y)-\mu(h \mid y) Q_{h}(y)>0,
\end{aligned}
$$

where use has been made of (10). Substituting from $(21), \bar{\pi}(1, y)>\bar{\pi}(0, y)$ if

$$
\bar{p}_{l}(y) Q_{l}(y)>\bar{p}_{h}(y) Q_{h}(y)
$$

Recalling proposition 2 , this proves $b(y)=\psi^{*}(y, \phi)$.

Proof of lemma 2: If $y$ is conclusive, the only credible announcement under the rules of proof is $b(y)=\psi^{*}(y, \phi)$. We therefore consider the selfsignalling condition only for the cases where $y$ is mixed. Let $\bar{\pi}\left(b, b^{\prime} \mid y\right)$ be the judge's expected payoff when he announces $d(y, \phi)=b^{\prime}$, which the parties are assumed to believe, although the judge knows he will play $d(y, \phi)=b$ where the play of $b$ is taken as exogenous. Announcements are self-signalling if $\bar{\pi}(b, b \mid y) \geq \bar{\pi}\left(b, b^{\prime} \mid y\right)$ for all $b, b^{\prime} \in\{0,1\}, b \neq b^{\prime}$.

Denoting by $d \in\{0,1\}$ the actual decision at the close of the trial,

$$
\bar{\pi}\left(b, b^{\prime} \mid y\right)=\mu(h \mid y) \operatorname{Pr}\left(d=0 \mid b, b^{\prime}, y, h\right)+\mu(l \mid y) \operatorname{Pr}\left(d=1 \mid b, b^{\prime}, y, l\right),
$$


where the $\mu(j \mid y)$ 's are the judge's beliefs about the defendant's care level, as defined in (21), and where the conditional probabilities $\operatorname{Pr}\left(\cdot \mid b, b^{\prime}, y, j\right)$ are determined by the continuation game.

When the complete evidence is disclosed, the sequentially optimal action under the rules of proof is $d(y, z)=\psi^{*}(y, z)$. Since $y$ is mixed,

$$
\sum_{z \in Z(y)}\left[p_{l}(y, z)-p_{h}(y, z)\right] \psi^{*}(y, z)>0
$$

and

$$
\sum_{z \in Z(y)}\left[p_{l}(y, z)-p_{h}(y, z)\right]\left[1-\psi^{*}(y, z)\right] \leq 0 .
$$

Given the belief that the judge will adjudicate according to $b^{\prime}$, the parties have dominant disclosure strategies, the argument being the same as in the proof of proposition 5. Combining this with the judge's actual play of $d(y, \phi)=b$ and his sequentially optimal decision when the complete evidence is disclosed, we obtain

$$
\operatorname{Pr}\left(d=1 \mid b, b^{\prime}, y, j\right)=\left\{\begin{array}{l}
0 \text { if } b=0, b^{\prime}=1 ; \\
1 \text { if } b=1, b^{\prime}=0 ; \\
v \sum_{z \in Z(y)} p_{j}(z \mid y) \psi^{*}(y, z) \text { if } b=b^{\prime}=0 ; \\
1-u \sum_{z \in Z(y)} p_{j}(z \mid y)\left[1-\psi^{*}(y, z)\right] \text { if } b=b^{\prime}=1 .
\end{array}\right.
$$

Consider the first line. When $b^{\prime}=1$, the plaintiff discloses nothing, the defendant discloses only favorable evidence (if he can). Thus, disclosure of the complete evidence can only lead to $d=0$. If no additional evidence is disclosed, the judge carries out his plan to play $d(y, \phi)=b=0$. It follows that the outcome is $d=0$ for sure. The argument for the other lines is similar.

Substituting in (22) yields

$$
\bar{\pi}(0,1 \mid y)=\mu(h \mid y)
$$




$$
\begin{array}{r}
\bar{\pi}(0,0 \mid y)=\mu(h \mid y)\left[1-v \sum_{z \in Z(y)} p_{h}(z \mid y) \psi^{*}(y, z)\right] \\
+\mu(l \mid y) v \sum_{z \in Z(y)} p_{l}(z \mid y) \psi^{*}(y, z)
\end{array}
$$

and therefore

$$
\bar{\pi}(0,0 \mid y)-\bar{\pi}(0,1 \mid y)=v \sum_{z \in Z(y)}\left[\mu(l \mid y) p_{l}(z \mid y)-\mu(h \mid y) p_{h}(z \mid y)\right] \psi^{*}(y, z)
$$

Substituting for the $\mu(j \mid y)$ 's from (21) finally yields

$$
\bar{\pi}(0,0 \mid y)-\bar{\pi}(0,1 \mid y)=v \sum_{z \in Z(y)}\left[\frac{p_{l}(y, z)-p_{h}(y, z)}{\bar{p}_{h}(y)+\bar{p}_{l}(y)}\right] \psi^{*}(y, z)>0,
$$

where the sign follows from (23).

Using (24), a similar argument shows that

$$
\bar{\pi}(1,1 \mid y)-\bar{\pi}(1,0 \mid y)=u \sum_{z \in Z(y)}\left[\frac{p_{h}(y, z)-p_{l}(y, z)}{\bar{p}_{h}(y)+\bar{p}_{l}(y)}\right]\left[1-\psi^{*}(y, z)\right] \geq 0,
$$

completing the proof.

\section{References}

Aumann, R. (1990), "Nash equilibria are not self-enforcing", in Economic Decision-Making: Games, Econometrics and Optimization, J. J. Gabszewicz, J.-F. Richard and L. A. Wolsey (eds.), Elsevier, Amsterdam.

Baliga, S. and S. Morris (2002), "Co-ordination, spillovers, and cheap talk", Journal of Economic Theory 105, 450-468.

Bernardo, A. E. , E. Talley, and I. Welch (2000), "A theory of legal presumptions", Journal of Law, Economics, and Organization 16, 1-49.

Bernhardt, D. and E. Nosal (2004), "Near-sighted justice", Journal of Finance 59(6), 2655-2684. 
Block, M. K. and J. S. Parker (2004), "Decision making in the absence of successful fact finding: theory and experimental evidence on adversarial versus inquisitorial systems of adjudication", International Review of Law and Economics 24, 89-105.

Bull, J. and J. Watson (2004), "Evidence disclosure and verifiability", Journal of Economic Theory 118, 1-31.

Clermont, K. M. and E. Sherwin (2002), "A comparative view of standards of proof", American Journal of Comparative Law 50, 243-275.

Daughety, A. F. and J. F. Reinganum (1995), "Keeping society in the dark: on the admissibility of pretrial negotiations as evidence in court", Rand Journal of Economics 26, 203-221.

Daughety, A. F. and J. F. Reinganum (2000a), "On the economics of trials: adversarial process, evidence, and equilibrium bias", Journal of Law, Economics and Organization 16, 365-395.

Daughety, A. F. and J. F. Reinganum (2000b), "Appealing judgments", Rand Journal of Economics 31, 502-526.

Demougin, D. and C. Fluet (2006), "Preponderance of evidence", European Economic Review 50, 963-976.

Demougin, D. and C. Fluet (2005), "Deterrence versus judicial error: a comparative view of standards of proof" Journal of Institutional and Theoretical Economics 161(2), 193-206.

Dewatripont, M. and J. Tirole (1999), "Advocates", Journal of Political Economy 107, 1-39.

Farrell, J. and M. Rabin (1996), "Cheap talk", Journal of Economic Perspectives 10, 103-118. 
Fluet, C. (2003), "Enforcing contracts: should courts seek the truth?", Journal of Institutional and Theoretical Economics 159, 49-69.

Froeb, L. K. and B. H. Kobayashi (2001), "Evidence production in inquisitorial vs. adversarial regimes", Economics Letters 66, 267-272.

Hay, B. L. and K. E. Spier (1997), "Burdens of proof in civil litigation: an economic perspective", Journal of Legal Studies 26, 413-431.

Jolowicz, J. A. (2000), On Civil Procedure, Cambridge University Press, Cambridge.

Jolowicz, J. A. (2003), "Adversarial and inquisitorial models of civil procedure", International Comparative Law Quarterly 52, 281-295.

Lando, H. (2002), "When is the Preponderance of the Evidence Standard Optimal?", Geneva Papers on Risk and Insurance 27(4), 602-608.

Lewis, T. and M. Poitevin (1997), "Disclosure of information in regulatory proceedings", Journal of Law, Economics, and Organization 13, 50-73.

Milgrom, P. and J. Roberts (1986), "Relying on the information of interested parties", Rand Journal of Economics 17, 18-32.

Palumbo, G. (2001), "Trial procedures and optimal limits on proof-taking", International Review of Law and Economics 21, 309-327.

Parisi, F. (2002), "Rent-seeking through litigation: adversarial and inquisitorial systems compared", International Review of Law and Economics 22, 193-216.

Posner, R. A. (1999), "An economic approach to the law of evidence", Stanford Law Review 51, 1477-1546.

Rubinfeld, D. L. and E. M. Sappington (1987), "Efficient awards and standards of proof in judicial proceedings", Rand Journal of Economics 18, 308-315. 
Sanchirico, C. W. (2001a), "Character evidence and the object of trial", Columbia Law Review 101(6), 1227-1311.

Sanchirico, C. W. (2001a), "Relying on the information of interested - and potentially dishonest-parties", American Law and Economics Review $3(2), 320-357$.

Schrag, J. (1999), "Managerial judges: an economic analysis of the judicial management of legal discovery", Rand Journal of Economics 30(2), 305-323.

Schrag, J. and S. Scotchmer (1994), "Crime and prejudice: The use of character evidence in criminal trials", Journal of Law, Economics and Organization 10, 319-342.

Shavell, S. (1989), "Optimal sanctions and the incentive to provide evidence to a legal tribunal", International Review of Law and Economics 9, 311.

Shin, H. S. (1994), "The burden of proof in a game of persuasion", Journal of Economic Theory 64, 253-264.

Shin, H. S. (1998), "Adversarial and inquisitorial procedures in arbitration", Rand Journal of Economics 29, 378-405.

Sobel, J. (1985), "Disclosure of evidence and resolution of disputes: who should bear the burden of proof?, in A. E. Roth, Ed., Game Theoretic Models of Bargaining, Cambridge University Press, Cambridge, 341361. 


\section{CESifo Working Paper Series}

(for full list see www.cesifo-group.de)

1948 C. Mirjam van Praag and Bernard M. S. van Praag, The Benefits of Being Economics Professor A (and not Z), March 2007

1949 Astrid Hopfensitz and Frans van Winden, Dynamic Choice, Independence and Emotions, March 2007

1950 Guglielmo Maria Caporale and Luis A. Gil-Alana, A Multivariate Long-Memory Model with Structural Breaks, March 2007

1951 Mattias Ganslandt and Keith E. Maskus, Wholesale Price Discrimination and Parallel Imports, March 2007

1952 Michela Redoano, Fiscal Interactions Among European Countries. Does the EU Matter?, March 2007

1953 Stefan C. Wolter, Rémy Hübschi and Matthias Müller, Push or Pull? An Empirical Analysis of the Demand for Individual Project Grants from the Swiss National Science Foundation, March 2007

1954 Scott Alan Carson, African-American and White Inequality in the American South: Evidence from the $19^{\text {th }}$ Century Missouri State Prison, March 2007

1955 Peter Egger, Marko Koethenbuerger and Michael Smart, Do Fiscal Transfers Alleviate Business Tax Competition? Evidence from Germany, March 2007

1956 Panu Poutvaara and Lars-H. R. Siemers, Smoking and Social Interaction, March 2007

1957 Stephan Danninger and Fred Joutz, What Explains Germany's Rebounding Export Market Share?, March 2007

1958 Stefan Krasa and Mattias Polborn, Majority-efficiency and Competition-efficiency in a Binary Policy Model, March 2007

1959 Thiess Buettner and Georg Wamser, Intercompany Loans and Profit Shifting Evidence from Company-Level Data, March 2007

1960 Per Pettersson-Lidbom and Mikael Priks, Behavior under Social Pressure: Empty Italian Stadiums and Referee Bias, April 2007

1961 Balázs Égert and Carol S. Leonard, Dutch Disease Scare in Kazakhstan: Is it real?, April 2007

1962 Paul De Grauwe and Pablo Rovira Kaltwasser, Modeling Optimism and Pessimism in the Foreign Exchange Market, April 2007 
1963 Volker Grossmann and Thomas M. Steger, Anti-Competitive Conduct, In-House R\&D, and Growth, April 2007

1964 Steven Brakman and Charles van Marrewijk, It's a Big World After All, April 2007

1965 Mauro Ghinamo, Paolo M. Panteghini and Federico Revelli, FDI Determination and Corporate Tax Competition in a Volatile World, April 2007

1966 Inés Macho-Stadler and David Pérez-Castrillo, Optimal Monitoring to Implement Clean Technologies when Pollution is Random, April 2007

1967 Thomas Eichner and Ruediger Pethig, Efficient $\mathrm{CO}_{2}$ Emissions Control with National Emissions Taxes and International Emissions Trading, April 2007

1968 Michela Redoano, Does Centralization Affect the Number and Size of Lobbies?, April 2007

1969 Christian Gollier, Intergenerational Risk-Sharing and Risk-Taking of a Pension Fund, April 2007

1970 Swapan K. Bhattacharya and Biswa N. Bhattacharyay, Gains and Losses of India-China Trade Cooperation - a Gravity Model Impact Analysis, April 2007

1971 Gerhard Illing, Financial Stability and Monetary Policy - A Framework, April 2007

1972 Rainald Borck and Matthias Wrede, Commuting Subsidies with two Transport Modes, April 2007

1973 Frederick van der Ploeg, Prudent Budgetary Policy: Political Economy of Precautionary Taxation, April 2007

1974 Ben J. Heijdra and Ward E. Romp, Retirement, Pensions, and Ageing, April 2007

1975 Scott Alan Carson, Health during Industrialization: Evidence from the $19^{\text {th }}$ Century Pennsylvania State Prison System, April 2007

1976 Andreas Haufler and Ian Wooton, Competition for Firms in an Oligopolistic Industry: Do Firms or Countries Have to Pay?, April 2007

1977 Eckhard Janeba, Exports, Unemployment and the Welfare State, April 2007

1978 Gernot Doppelhofer and Melvyn Weeks, Jointness of Growth Determinants, April 2007

1979 Edith Sand and Assaf Razin, The Role of Immigration in Sustaining the Social Security System: A Political Economy Approach, April 2007

1980 Marco Pagano and Giovanni Immordino, Optimal Regulation of Auditing, May 2007

1981 Ludger Woessmann, Fundamental Determinants of School Efficiency and Equity: German States as a Microcosm for OECD Countries, May 2007 
1982 Bas Jacobs, Real Options and Human Capital Investment, May 2007

1983 Steinar Holden and Fredrik Wulfsberg, Are Real Wages Rigid Downwards?, May 2007

1984 Cheng Hsiao, M. Hashem Pesaran and Andreas Pick, Diagnostic Tests of Cross Section Independence for Nonlinear Panel Data Models, May 2007

1985 Luis Otávio Façanha and Marcelo Resende, Hierarchical Structure in Brazilian Industrial Firms: An Econometric Study, May 2007

1986 Ondřej Schneider, The EU Budget Dispute - A Blessing in Disguise?, May2007

1987 Sascha O. Becker and Ludger Woessmann, Was Weber Wrong? A Human Capital Theory of Protestant Economic History, May 2007

1988 Erkki Koskela and Rune Stenbacka, Equilibrium Unemployment with Outsourcing and Wage Solidarity under Labour Market Imperfections, May 2007

1989 Guglielmo Maria Caporale, Juncal Cunado and Luis A. Gil-Alana, Deterministic versus Stochastic Seasonal Fractional Integration and Structural Breaks, May 2007

1990 Cláudia Costa Storti and Paul De Grauwe, Globalization and the Price Decline of Illicit Drugs, May 2007

1991 Thomas Eichner and Ruediger Pethig, Pricing the Ecosystem and Taxing Ecosystem Services: A General Equilibrium Approach, May 2007

1992 Wladimir Raymond, Pierre Mohnen, Franz Palm and Sybrand Schim van der Loeff, The Behavior of the Maximum Likelihood Estimator of Dynamic Panel Data Sample Selection Models, May 2007

1993 Fahad Khalil, Jacques Lawarrée and Sungho Yun, Bribery vs. Extortion: Allowing the Lesser of two Evils, May 2007

1994 Thorvaldur Gylfason, The International Economics of Natural Resources and Growth, May 2007

1995 Catherine Roux and Thomas von Ungern-Sternberg, Leniency Programs in a Multimarket Setting: Amnesty Plus and Penalty Plus, May 2007

1996 J. Atsu Amegashie, Bazoumana Ouattara and Eric Strobl, Moral Hazard and the Composition of Transfers: Theory with an Application to Foreign Aid, May 2007

1997 Wolfgang Buchholz and Wolfgang Peters, Equal Sacrifice and Fair Burden Sharing in a Public Goods Economy, May 2007

1998 Robert S. Chirinko and Debdulal Mallick, The Fisher/Cobb-Douglas Paradox, Factor Shares, and Cointegration, May 2007

1999 Petra M. Geraats, Political Pressures and Monetary Mystique, May 2007 
2000 Hartmut Egger and Udo Kreickemeier, Firm Heterogeneity and the Labour Market Effects of Trade Liberalisation, May 2007

2001 Andreas Freytag and Friedrich Schneider, Monetary Commitment, Institutional Constraints and Inflation: Empirical Evidence for OECD Countries since the 1970s, May 2007

2002 Niclas Berggren, Henrik Jordahl and Panu Poutvaara, The Looks of a Winner: Beauty, Gender, and Electoral Success, May 2007

2003 Tomer Blumkin, Yoram Margalioth and Efraim Sadka, Incorporating Affirmative Action into the Welfare State, May 2007

2004 Harrie A. A. Verbon, Migrating Football Players, Transfer Fees and Migration Controls, May 2007

2005 Helmuth Cremer, Jean-Marie Lozachmeur and Pierre Pestieau, Income Taxation of Couples and the Tax Unit Choice, May 2007

2006 Michele Moretto and Paolo M. Panteghini, Preemption, Start-Up Decisions and the Firms' Capital Structure, May 2007

2007 Andreas Schäfer and Thomas M. Steger, Macroeconomic Consequences of Distributional Conflicts, May 2007

2008 Mikael Priks, Judiciaries in Corrupt Societies, June 2007

2009 Steinar Holden and Fredrik Wulfsberg, Downward Nominal Wage Rigidity in the OECD, June 2007

2010 Emmanuel Dhyne, Catherine Fuss, Hashem Pesaran and Patrick Sevestre, Lumpy Price Adjustments: A Microeconometric Analysis, June 2007

2011 Paul Belleflamme and Eric Toulemonde, Negative Intra-Group Externalities in TwoSided Markets, June 2007

2012 Carlos Alós-Ferrer, Georg Kirchsteiger and Markus Walzl, On the Evolution of Market Institutions: The Platform Design Paradox, June 2007

2013 Axel Dreher and Martin Gassebner, Greasing the Wheels of Entrepreneurship? The Impact of Regulations and Corruption on Firm Entry, June 2007

2014 Dominique Demougin and Claude Fluet, Rules of Proof, Courts, and Incentives, June 2007 